\title{
Northwest Open Automated Demand Response Technology Demonstration Project
}

\section{March 17, 2010}
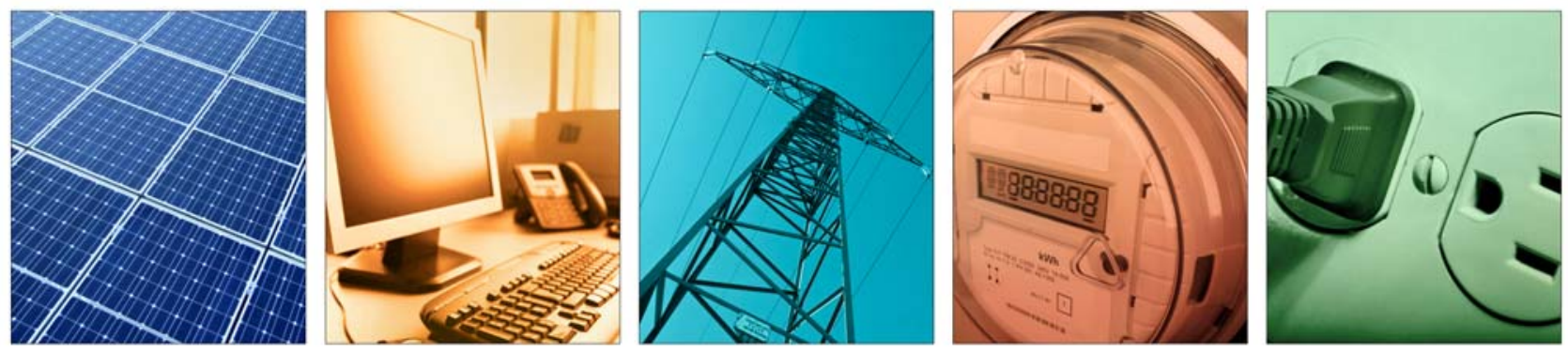

Funded by:

Bonneville Power Administration

Contact: Joshua Binus

Prepared by:

Sila Kiliccote, Mary Ann Piette, and Junqiao Dudley Lawrence Berkeley National Laboratory 


\section{Acknowledgments}

The work described in this report was funded by Bonneville Power Administration and Seattle City Light and by the U.S. Department of Energy under Contract No. DE-AC02$05 \mathrm{CH} 11231$. The authors are grateful for the extensive support from numerous individuals who assisted in this project:

- Joshua Binus and Pam Sporborg (Bonneville Power Administration)

- David Hsu and Jerry Raitzer (Seattle City Light)

- Paul Lipkin and Dan Hennage (Akuacom) for their development of the DR Automation Server System and their support in training, trouble shooting, and running the DR events

- Patty Anderson, Heather Helgen, Jon Sargeant (McKinstry) for their assistance in recruitment, installations, commissioning and data collection

This project could not have been completed without assistance from building owners, facility engineers, project managers, and technology developers. The following organizations provided assistance in this project:

- Target: Janeen Fettig

- Seattle Municipal Tower: Sarah Calvillo Hoffman, Kurt Sarchet, and Troy Taylor

- Seattle University: Lee Miley

- RREEF Alternative Investments (One Convention Place): Tom James

- Macy's: Jerry Aalbu, Doug Willard

- 4th \& Pike - Seaboard Building (Pine Street): Ashanti Bitar

- One Union: Rick Mock

- McKinstry: Mark Brenkle, Troy Heerwagen, Ron Fues; Electricians: Scott Weaver, David Shuman, Robert Brickell, Charles Simkulet, Joe Dugger, Bill Hinman, Dan Nuber, Clinton Olson, Dave Stellwagen, Peter Vetter, Walter Russell; Electrical Support (Dispatch, Meters): Brian Skinner, Cary Janz, Anne Neely (Facility Manager) \& David Minear (Facility Technician)

- Automated Logic Corporation: Ivan Kelava

- Alerton: Willis Gaines

- Siemens: Frank Bennett, Cassandra Beck, Kevin Templeton, Sam West, Tom Vanwinkle, Fair Eng

- Delta Controls/ESC Automation: Dave Amos

- Lawrence Berkeley National Laboratory: Nance Matson, David Watson, Rish Ghatikar, Janie Page 


\section{Table of Contents}

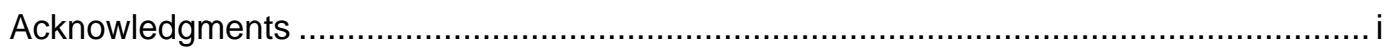

Executive Summary ............................................................................................ ii

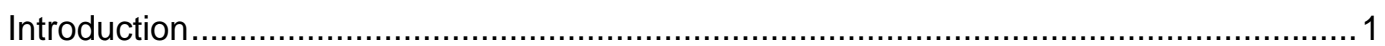

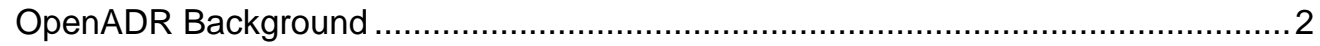

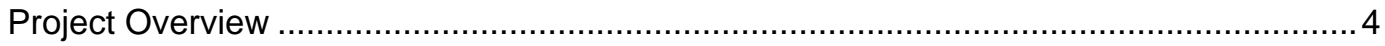

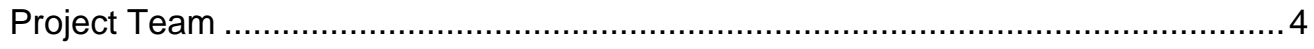

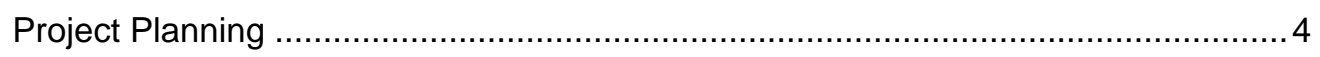

Automation Technology Description and Development........................................ 6

The DR Automation Server ...................................................................... 8

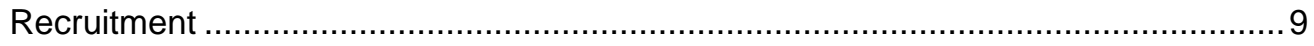

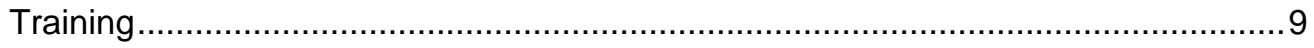

Technical Steps Toward Customer Enablement .................................................. 9

Testing and Commissioning Procedures ................................................................ 11

Operations During Demand Response Events..................................................11

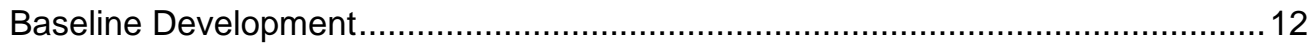

Summary of OpenADR Technology Performance ...................................................... 16

Building Systems and DR Strategies ............................................................... 16

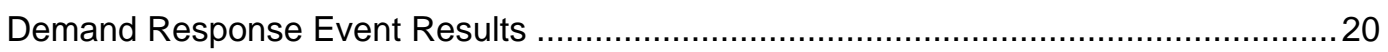

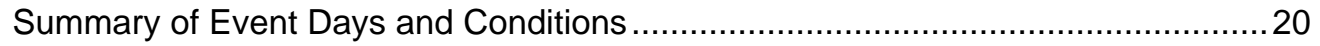

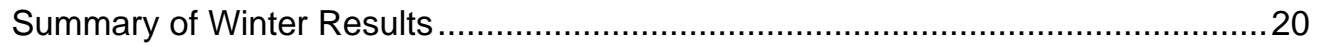

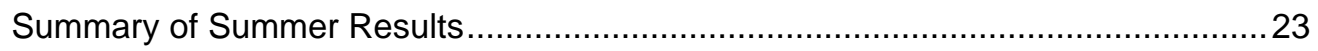

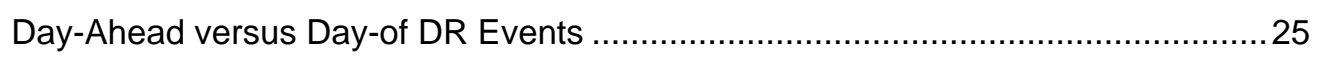

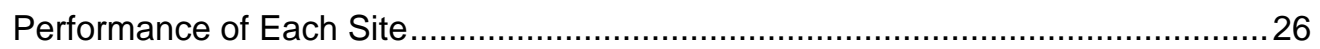

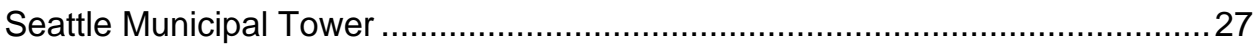

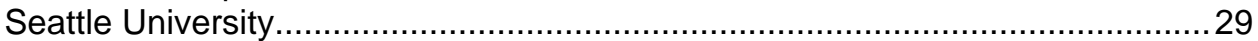

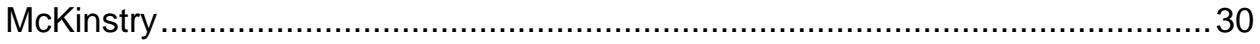

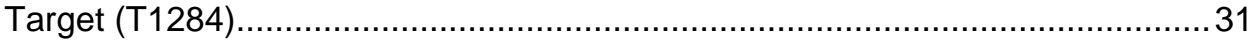

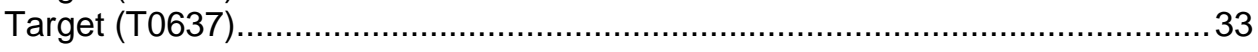

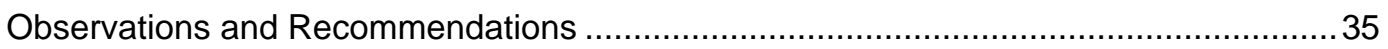

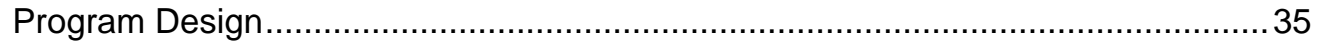

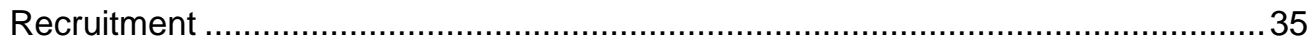

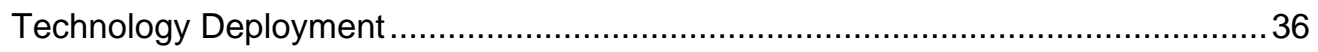

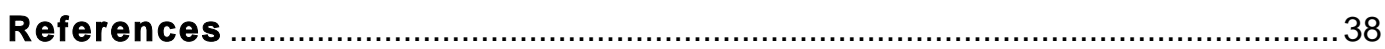

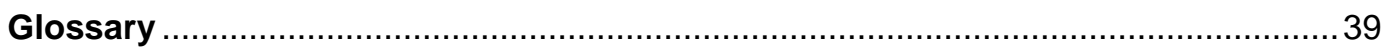




\section{Executive Summary}

The Lawrence Berkeley National Laboratory (LBNL) Demand Response Research Center (DRRC) demonstrated and evaluated open automated demand response (OpenADR) communication infrastructure to reduce winter morning and summer afternoon peak electricity demand in commercial buildings the Seattle area. LBNL performed this demonstration for the Bonneville Power Administration (BPA) in the Seattle City Light (SCL) service territory at five sites: Seattle Municipal Tower, Seattle University, McKinstry, and two Target stores.

This report describes the process and results of the demonstration.

OpenADR is an information exchange model that uses a client-server architecture to automate demand-response (DR) programs. These field tests evaluated the feasibility of deploying fully automated DR during both winter and summer peak periods. DR savings were evaluated for several building systems and control strategies.

This project studied DR during hot summer afternoons and cold winter mornings, both periods when electricity demand is typically high. This is the DRRC project team's first experience using automation for year-round DR resources and evaluating the flexibility of commercial buildings' end-use loads to participate in DR in dual-peaking climates. The lessons learned contribute to understanding end-use loads that are suitable for dispatch at different times of the year.

The project was funded by BPA and SCL.

BPA is a U.S. Department of Energy agency headquartered in Portland, Oregon and serving the Pacific Northwest. BPA operates an electricity transmission system and markets wholesale electrical power at cost from federal dams, one non-federal nuclear plant, and other non-federal hydroelectric and wind energy generation facilities. Created by the citizens of Seattle in 1902, SCL is the second-largest municipal utility in America. SCL purchases approximately $40 \%$ of its electricity and the majority of its transmission from BPA through a preference contract. SCL also provides ancillary services within its own balancing authority. The relationship between BPA and SCL creates a unique opportunity to create DR programs that address both BPA's and SCL's markets simultaneously.

Although simultaneously addressing both market could significantly increase the value of DR programs for BPA, SCL, and the end user, establishing program parameters that maximize this value is challenging because of complex contractual arrangements and the absence of a central Independent System Operator or Regional Transmission Organization in the northwest

\section{Methodology}

The project team recruited sites for the demonstration, developed control strategies for the sites, deployed and enhanced the automation system, and evaluated the sites' participation in DR events. McKinstry assisted with recruitment, site surveys, strategy development, commissioning, and participant and control vendor management. Akuacom established a new DR automation server (DRAS) and enhanced its operations to allow for scheduling winter morning day-of and day-ahead DR events as well as geographical location differentiation among the DR resources. Sites received payment for participating in the project. Each facility and control vendor worked with LBNL and McKinstry to select and implement DR control strategies and develop automation.

Once the automated DR strategies were programmed, they were commissioned and electric meter data and trend logs were collected from the energy management and control systems (EMCSs) of each site. The DRAS allowed the sites to receive day-ahead and day-of proxies for price that indicated DR events.

\section{Results}

- Lighting provides year-round DR. Lighting load-sheds have fast ramp times and thus can provide excellent year-round DR although the change in lighting level is detectable by 
building occupants. However, centralized controls are necessary for DR with lighting systems, and most lighting control systems are not centralized. Most new lighting control systems that integrate with daylighting in commercial buildings have local, closed-loop controls.

- Heating ventilation and air conditioning (HVAC) systems with natural gas heating have limited savings opportunities for winter DR. Two buildings with gas-powered rooftop units (RTUs) selected duty cycling as a DR strategy. The DR opportunities in gas heating systems come from fan power savings (by contrast, electric heating systems offer good savings possibilities from fan power, see below).

- All-electric heating systems offer good opportunities for winter DR. A global zonetemperature adjustment strategy, which is often used in California to reduce peak demand during summer afternoons, performed well in the electrically heated building in this study. Zone temperatures were temporarily reduced to minimize electrical loads.

- OpenADR communication infrastructure is applicable to both winter and summer DR in commercial buildings. On average, using an outside air temperature regression (OATR) baseline, the buildings that participated in the winter DR events delivered $14 \%$ demand reduction per site or 0.59 watts per square foot $\left(\mathrm{W} / \mathrm{ft}^{2}\right)$ over three hours. The summer DR events delivered at least $16 \%$ demand reduction per site or $0.47 \mathrm{~W} / \mathrm{ft}^{2}$ over five hours. HVAC and lighting systems appear to present major opportunities for automated DR in commercial buildings in Seattle for both winter and summer loads. In this study, HVAC systems both with and without electric heating offered DR opportunities because significant savings from fan power in both seasons are possible Average demand reductions for winter and summer events were 767 kilowatts (kW) and $338 \mathrm{~kW}$, i.e., 14\% and 16\% average peak load, respectively. Figure ES-1 and Figure ES-2 show the aggregate load profiles for winter and summer. Note that although the base load remains similar, the shapes of the loads and peak periods differ significantly in each season.

TABLE ES-1. Summary of winter and summer DR events using outside air temperature regression baseline

\begin{tabular}{|l|r|r|}
\hline & \multicolumn{1}{|c|}{ Winter } & \multicolumn{1}{|c|}{ Summer } \\
\hline \hline Average demand reduction (kW) for each DR event & $767 \mathrm{~kW}$ & $338 \mathrm{~kW}$ \\
\hline Total energy savings from four DR events (kWh) & $8,589 \mathrm{kWh}$ & $6,455 \mathrm{kWh}$ \\
\hline Average per customer cost for control and commissioning & $\$ 4,057$ & $\$ 4,962$ \\
\hline Average control and commisionning cost per kW (one time) & $\$ 76 / \mathrm{kW}$ & $\$ 108 / \mathrm{kW}$ \\
\hline
\end{tabular}




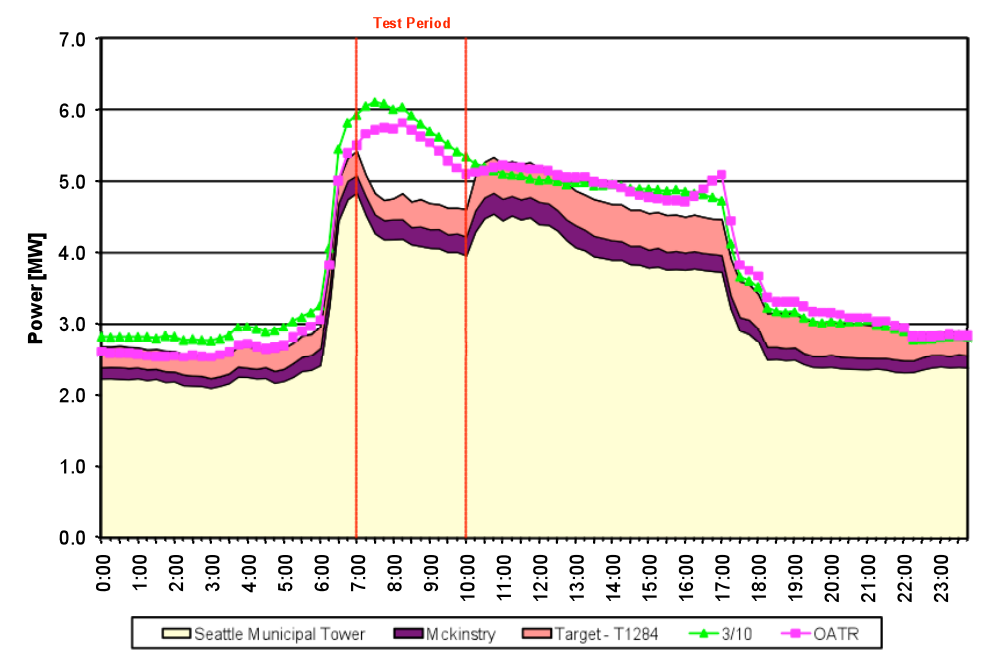

Figure ES-1. Aggregate load reduction in winter

- Commissioning of DR strategies plays an important role in DR's success in dualpeaking regions. During the DR tests, the sites did not have a way to trigger the 'event pending' signal through their interface (the "mysite" webpage). Experience from the summer DR tests shows that customers need to be able to replicate all DR operating modes (DR event pending, DR strategy active, and DR strategy idle) to properly commission and test the control strategies. A significant finding is the importance of having the ability to trigger the "pending" signal manually during commissioning so that strategies are accurately translated into control systems. Commissioning of all the signals prior to testing improves the reliability of DR strategies.

- DR works best in well-tuned buildings. For one building where the DR performed well in the winter, the summer DR strategies did not perform well because the sequence of operations did not maintain zone temperatures.

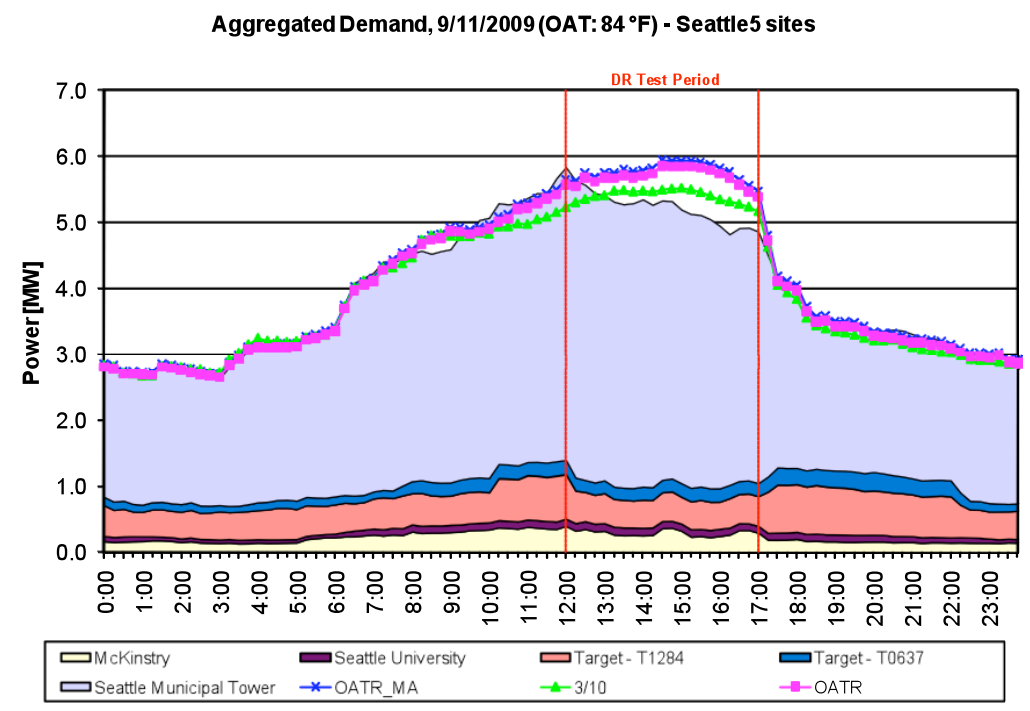

Figure ES-2. Aggregate load reduction in summer 
- Recruitment is a lengthy and ongoing effort. The team's experience in the northwest was similar to experiences with early field test recruitment in California. Recruitment is part education and part relationship building. DR participants must be comfortable that:

- $\quad$ service levels in their facilities will be modified for periods of time;

- ongoing assistance and monitoring will be available to help them select detectable but acceptable DR strategies; and

- strategies can be modified following DR events, and participants can choose not to participate in an individual event by opting out through the DRAS internet portal.

- A large potential pool of customers enabled us to enroll the targeted number of participants. Of 11 facilities initially surveyed, eight sites indicated interest in participating. Of these eight, three could not participate in the test events because of one or more of the following:

- Limitations of control systems and the cost of overcoming these limitations,

- Communication problems within control systems that prevented the research team from monitoring and collecting data from each test DR event, or

- Concerns from tenants.

\section{Recommendations and Future Directions}

This project is an initial step in evaluating the flexibility and automation of building end-use loads for participating in both winter and summer DR events. The project tests demonstrated that OpenADR systems can be deployed for different seasons and demonstrated OpenADR's performance during seasonal electricity demand peaks. Both end-use customers and controls companies need guidance and education in: understanding DR concepts; evaluating DR end-use control strategies; and developing, implementing, and testing DR options. After an initial investment in education and technologies, OpenADR delivers consistently triggered and repeatable DR over time.

As a next step, LBNL recommends that SCL and BPA consider enhancing whole-building energy simulation tools for estimating DR capabilities for buildings in hot summer climates in order to support the estimation of cold-winter-morning DR capabilities in commercial buildings. For the long term, the main recommendations are to encourage SCL to expand the DR project in downtown Seattle area and to encourage BPA to facilitate the expansion of OpenADR within their control area. Most importantly, the local and regional value of DR must be characterized to develop automated DR programs. The project team's main recommendations are summarized below:

1. Interval meters are required for measurement and verification of DR participation. Many large buildings in downtown Seattle that have meters that record customer data at regular intervals as well as internet access to the data (through SCL's MeterWatch program) are excellent candidates to participate in an expansion of this project.

2. Establish an education package to accompany DR efforts: Extensive customer education and outreach are required for DR programs, including explanations of why DR is necessary, how customers can respond and how they will be compensated. SCL would like to use OpenADR for reliability purposes, so the value stream for both the utility and the customer should be considered.

3. Successful technology deployment requires a workforce that understands the technology and the new ways of using it, so the team recommends education for controls vendors on DR, the OpenADR communication platform, and DR strategies. 
4. Commissioning building systems and DR strategies is important to DR's success. DR programs can be incorporated during retrocommissioning programs. Before the retrocommissioning team leaves a project, the team can work with the customer to develop, implement, and commission DR strategies. The added cost as part of a retrocommissioning project is expected to be lower than the cost of stand-alone individual DR projects.

5. Although this project evaluated DR strategies for winter and summer peak demand, with hydro power and wind integration, more DR may be needed during swing seasons. The local and regional need for and value of DR should be determined and taken into account when DR programs are designed and automated.

Three electric utilities currently use OpenADR to automate their DR programs, and it has been adopted by a wide range of building and industrial controls companies. It is also identified by the U.S. Department of Energy (DOE) as one of "the initial batch of 16 National Institute of Standards and Technology (NIST)-recognized interoperability standards announced on May 18, 2009" which "will help ensure that software and hardware components from different vendors will work together seamlessly, while securing the grid against disruptions." A detailed specification for OpenADR was developed over a two-year period and released as an official California Energy Commission and Lawrence Berkeley National Laboratory (LBNL) report (http://openadr.lbl.gov/pdf/cec-500-2009-063.pdf). The OpenADR specification will be the basis for ongoing DR communications standards development efforts within both the Organization for the Advancement of Structured Information Standards (OASIS - http://www.oasis-

open.org/home/) and the UCA International Users Group (UCAlug - http://www.ucaiug.org/). Both of these highly regarded organizations are active within the emerging "Smart Grid" domain. With ongoing efforts of OASIS and UCAlug, OpenADR is on a path to become a formal standard within organizations such as the International Electrotechnical Commission (IEC - http://www.iec.ch/).

\footnotetext{
${ }^{1}$ http://www.energy.gov/news2009/7408.htm
} 


\section{Introduction}

Experience in California has shown that commercial building owners and facility managers have limited understanding how to operate their facilities to reduce their electricity costs under demand response (DR) programs. Lawrence Berkeley National Laboratory (LBNL), through the California Energy Commission Public Interest Energy Research-funded Demand Response Research Center (DRRC) as well as utility-funded activities, has researched and demonstrated that priceresponse can be automated using standard eXtensible markup language (XML)-based communications with customer-owned control systems. Fully automated DR accounts for more

\section{Many end-use customers have suggested that automation would help them institutionalize their electric demand reduction.} than $60 \mathrm{MW}$ of peak demand savings in California, provided by more than 200 customer facilities (Wikler et al. 2009). Many end-use customers have suggested that automation would help them institutionalize their electricity demand reduction.

The overall goal of the research documented in this report is to develop, demonstrate, and evaluate DR technologies and strategies for commercial buildings in the Pacific Northwest.

DR is an important least-cost resource for the northwest's Bonneville Power Administration (BPA) to meet peak demand. Although BPA has historically been able to meet peak load through the flexibility of its hydro system, continued load growth, wind power integration, and fish operations are stretching this capacity. DR is proven resource that can add both flexibility and capacity back to BPA's system. With a long history of successful demand-side management/energy-efficiency programs, BPA is well positioned to develop a DR resource to meet the changing needs of the northwest power system.

This study focused on automated DR, activated by an emergency signal, for hot summer afternoon and cold winter morning peak demand periods at several demonstration sites in the Seattle area, served by Seattle City Light (SCL). The relationship between BPA and SCL creates a unique opportunity to create DR programs that address both BPA's and SCL's markets simultaneously. The project was funded by BPA and SCL.

The DR signals ${ }^{2}$ for this project were published on a single web services server, available on the Internet using the meta-language, XML. Each of the five participating facilities - Seattle Municipal Tower (SMT), Seattle University, McKinstry, and two Target stores - monitored the DR signal using a web services client application and automatically shed site-specific electrical loads when the proxy price increased. This project demonstrated use of the Open Automated Demand Response Communication Specification (version 1.0) which is designed to facilitate DR automation without human intervention (Piette et al. 2009).

This project studied DR during hot summer afternoons and cold winter mornings, both periods when electricity demand is typically high. This is the DRRC project team's first experience using automation for year-round DR resources and evaluating the flexibility of commercial buildings' end-use loads to participate in DR in dual-peaking climates. The lessons learned contribute to understanding end-use loads that are suitable for dispatch at different times of the year.

The structure of the remainder of this report is as follows. The remaining sections of this Introduction summarize previous work, additional background, and the project objectives. The Project Overview section describes the project team and planning and the technology used for the automation as well as the DR event design and steps for participation. The Summary of OpenADR Technology Performance section outlines issues with communication and DR

\footnotetext{
${ }^{2}$ DR events were mapped onto price signals. Price signals used for this project were: "Normal," indicating no change in the participants' actual rates, or "High," indicating a peak demand problem on the electricity grid.
} 
automation server operations. Demand Response Event Results presents aggregate results from the winter and summer DR events as well as best and worst performances for each season for each site. Performance is compared to a trend point analysis, and the findings for each site are summarized. Observations and Recommendations presents key findings relative to the project objectives as well as recommendations and next steps.

\section{OpenADR Background}

DRRC has been working with California utilities to develop a low-cost automation infrastructure to improve DR capability, evaluate the readiness of buildings

About $15 \%$ of the time, the person in charge of responding to demand response events is not at the facility. to receive price and reliability signals, and assess control capabilities of current and future buildings. DR experience in California has shown that customers have limited knowledge of how to operate their facilities to reduce their electricity costs under critical peak pricing (Quantum and Summit Blue 2004). While the lack of knowledge about how to develop and implement DR control strategies is one barrier to participation in DR programs, another barrier is the lack of automation of DR systems. Most DR activities are manual and require building operations staff to first receive signals (emails, phone calls, pager signals) and then to act on these signals to execute DR strategies. About $15 \%$ of the time, the person in charge of responding to the DR events is not at the facility (Quantum and Summit Blue 2004), which is a significant obstacle to reliable manual response to DR signals.

The levels of DR automation can be defined as follows (Piette et al. 2005). Manual Demand Response is a labor-intensive approach, e.g., manually turning off or changing comfort set points at each equipment switch or controller. Semi-Automated Demand Response involves a preprogrammed DR strategy initiated by a person via a centralized control system. Fully

Automated Demand Response does not involve human intervention and is initiated by an external communications signal. The receipt of the external signal starts pre-programmed DR strategies. We refer to this as Auto-DR.

OpenADR, which was the focus of this study, refers to an open, secure, two-way information exchange model that is used to implement Auto-DR by publishing price and reliability signals for DR applications to building control systems.

One important concept in Auto-DR is that a facility manager should be able to "opt out" or "override" a DR event if the event comes at time when the reduction in end-use services is not

\section{Examples of demand response strategies include reducing electrical loads, for example, by dimming or turning off non-critical lights, changing comfort thermostat set points, and turning off non-critical equipment.} desirable.

California's experience with DR automation infrastructure led LBNL to develop open and interoperable specifications and to work with standards organizations to facilitate the adoption of these specifications as a standard. (http://openadr.lbl.gov/pdf/cec-500-2009-063.pdf). The OpenADR specification will be the basis for ongoing DR communications standards development efforts within both the Organization

for the Advancement of Structured Information Standards (OASIS - http://www.oasisopen.org/home/) and the UCA International Users Group (UCAlug - http://www.ucaiug.org/). Both of these highly regarded organizations are active within the emerging "Smart Grid" domain. With ongoing efforts of OASIS and UCAlug, OpenADR is on a path to become a formal standard within organizations such as the International Electrotechnical Commission (IEC - http://www.iec.ch/).

From the customer side, the site's electrical load shape can be modified for DR by modifying enduse loads. Examples of DR strategies include reducing electrical loads, for example by dimming 
or turning off non-critical lights, changing comfort thermostat set points, and turning off non-critical equipment. In automated DR systems, these activities are triggered by specific actions by the utility or other electricity service provider, such as dynamic pricing or demand bidding. Many electricity customers have suggested that automation would help them institutionalize their DR. LBNL research has found that many building Energy Management and Control Systems (EMCSs) and related lighting and other controls can be pre-programmed to manage DR.

Three electric utilities currently use OpenADR to automate their DR programs, and it has been adopted by a wide range of building and industrial controls companies. It is also identified by the U.S. Department of Energy as one of "the initial batch of 16 National Institute of Standards and Technology (NIST)-recognized interoperability standards announced on May 18, 2009" which "will help ensure that software and hardware components from different vendors will work together seamlessly, while securing the grid against disruptions. 


\section{Project Overview}

The objectives of this project were to:

1. Demonstrate how an automated notification system can be used for DR in large commercial facilities.

2. Evaluate what types of DR shifting and shedding strategies can be automated for winter and summer DR events.

3. Identify optimal control and shedding strategies for winter and summer events.

4. Determine occupant/tenant responses, if any, to these strategies (so they can be fine tuned if disruptive to occupant/tenant activities).

\section{Project Team}

The members of the project team and their roles and responsibilities are identified below:

Bonneville Power Administration (BPA) a U.S. Department of Energy agency headquartered in Portland, Oregon and serving the Pacific Northwest. BPA operates an electricity transmission system and markets wholesale electrical power at cost from federal dams, one non-federal nuclear plant, and other non-federal hydroelectric and wind energy generation facilities. BPA participated in finalizing the project plan and test plan; provided ongoing support, including technical and design assistance for key milestones in project design and execution; and evaluated the project's relevance to regional DR plans. BPA also reviewed and approved project deliverables.

Seattle City Light (SCL) was created by the citizens of Seattle in 1902 and is the second-largest municipal utility in America. SCL purchases approximately $40 \%$ of its electricity and the majority of its transmission from BPA through a preference contract. SCL also provides ancillary services within its own balancing authority. SCL assisted in project planning and management. SCL helped fund the project by: a) providing financial incentives to the DR sites; b) leading site recruitment; and c) sharing project implementation costs. SCL also assisted in project execution, especially on-the-ground activities.

LBNL's DRRC is funded by the California Energy Commission Public Interest Energy Research program and utilities utility-funded activities. The LBNL DRRC team developed and executed the final project plan, developed evaluation methods, collected data, performed analysis, and drafted the final report.

Akuacom (subcontractor to LBNL) provides technology and services for Automated Demand Response (Auto-DR). Akuacom modified its DR Automation Server (DRAS) to accommodate SCL tests, monitored the DRAS during tests, and provided ongoing technical support for automation.

McKinstry (subcontractor to LBNL) is a full-service design, build, operate and maintain (DBOM) firm with over 1,600 employees. McKinstry assisted LBNL with recruitment by conducting DR audits, working with control vendors to determine DR strategies, and establishing DR communication. McKinstry was instrumental in conducting tests and evaluating test results.

\section{Project Planning}

In preparation for DR test days, the participating sites worked with SCL and LBNL on the following tasks:

Conducting Training: LBNL and Akuacom scheduled a one-day training session with BPA, SCL, and McKinstry, who conducted the DR audits and worked with each site to prepare facilities for test events. LBNL also trained control vendors on DR strategies and connectivity issues before the winter and summer tests. 
Conducting Recruitment: The goal was to recruit four to six different types of facilities with varying heating, ventilation, and air conditioning (HVAC) systems. SCL and McKinstry identified and approached facility managers. Each site was offered a DR audit to determine whether the site would be a "good candidate" for the study. For the winter tests, a "good candidate" was identified as one that had loads in the morning periods and could be ready for testing by the beginning of February. Out of 11 sites that were initially approached, five participated in the winter tests and were recruited again for the summer tests. Each site signed a memorandum of agreement (MOA) designed by SCL for mutual communication purposes. The MOA ensured that participants understood the SCL/LBNL collaboration agreement, ensured the payment of the participation incentive, and outlined roles, expectations, and payment milestones. Sites with interval meters and connection to SCL's MeterWatch utility information system were preferred.

Collecting Data: LBNL collected site surveys (Kiliccote et al. 2009) from each participant as well as mechanical and electrical drawings when available. In addition, LBNL requested trend logs relevant to the DR strategies development. Each site had archived data from electric meters, EMCSs, or Energy Information Systems (EISs), or the team installed a meter for the duration of the project. Of the five sites, only one was on SCL's MeterWatch program with on-line access to 15-minute interval data. LBNL project staff was given full access to data.

Defining Shed Strategies: Successful strategies that had been used previously in California for summer afternoon peaking facilities included global zone temperature adjustment, duct static pressure reset, variable frequency drive position limiting, chilled water valve position limiting, and reductions in lighting levels. The team encouraged participating facilities to develop innovative summer and winter shed strategies that were appropriate for each facility.

Updating Demand Response Automation Server: Akuacom/LBNL updated the DRAS functionality and user interface to accommodate BPA's and SCL's requirements for the test events.

Establishing Automation Connectivity: Each site was outfitted to receive the LBNL/Akuacomgenerated price proxy signals (or the associated operational mode signals) by one of two methods:

1. If the participating site already had an EMCS/EIS to the Internet, then that connection was used, or

2. A Client Logic Integrated Relay (CLIR) box was installed if no such connection existed at the site.

Programming Shed Strategies into EMCS: Each facility's EMCS vendor was hired to program the load-sheds desired in response to a rise in price signal. McKinstry and LBNL oversaw this activity and coordinated it with the controls vendors. LBNL also worked with the controls vendors to set up trend logs in the facilities to record key control points for DR strategy implementation. After the events, the trend logs were matched with the implemented DR strategy to confirm that the test events took place and the EMCS responded as programmed.

\section{During the Test}

DR Event Triggers: During the winter and summer test periods SCL system operators determined the event start and end times. Akuacom, acting on behalf of these researchers, sent DR test notifications to each participant. Winter DR events started at 7 a.m. and ended at 10 a.m. The events were dispatched based on the minimum outside air temperature during the DR period. At the beginning of each week, DR events were scheduled for the coldest days of the week as predicted in weather forecasts. Summer DR events started at noon and ended at 5 p.m. The events were called when the forecast temperature exceeded $80^{\circ} \mathrm{F}$ although one DR event was dispatched on a $78^{\circ} \mathrm{F}$ day because the team thought that there would not be any warmer days during the period. 
For day-ahead tests, participants received notifications at 3 p.m. previous day, and, for day-of events, participants received notifications 30 minutes prior to the event start time. There were a total of four test events for each season: three day-ahead tests and one day-of test. During the winter tests, the test days for each site did not coincide because sites were tested as soon as they were enabled so the team could capture the coldest mornings. During the summer tests, sites were enabled around the same time, so more sites participated in each test event.

\section{After the Test}

Documenting Shed: LBNL and McKinstry collected whole-building electricity consumption data for each site in the project. When detailed data were available from an EMCS or other end-use meters, the team also collected those data to help in understanding the dynamics of the shed strategies. LBNL studied load profiles and weather and load data and used several baseline methods to evaluate sheds at each site.

Participant Interviews: LBNL, with McKinstry's assistance, contacted each site to record reactions to the DR strategies and any comfort complaints.

\section{Automation Technology Description and Development}

The steps involved in the Auto-DR process during DR events are:

1. DRAS operator issues a DR event.

2. DR event is published on the DRAS.

3. DRAS clients (CLIR or web service) request event data from the DRAS every minute.

4. Customized pre-programmed DR strategies determine action based on event price/mode.

5. Facility EMCS carries out load reduction based on DR event signals and strategies.

OpenADR systems use an XML-based web-service-oriented architecture for platform-

independent, interoperable systems. For more information about each of the above steps, see the "Technical Steps to Enable Customer Participation" subsection below.

The DRAS can initiate DR control strategies through almost any control system. The OpenADR specification is published, and the DRAS web services client template is made available to software client developers to facilitate interfacing of systems to the DRAS (Piette et al. 2009). Sample files and descriptions are in the public domain. The client software continuously polls the DRAS to determine the timing and magnitude of DR events. Logic to shift or shed electrical loads based on DR signals and connectivity to each system is created using the existing control systems, based on each site's requirements. 
To maintain confidentiality and integrity of customer information, the HTTPS uses 128-bit encryption to secure data during transmission via the Internet.
The security used for DRAS and DRAS clients addresses confidentiality, authentication, and integrity. The data communications between the DRAS and the DRAS clients within facilities is secured using Secure Hyper Transfer Text Protocol (HTTPS) and authenticated using certificates, username, and password. To maintain the confidentiality and integrity of customer information, the HTTPS uses 128-bit encryption so data are secure during transmission via the internet. Username and password

authentication ensures that communications are only allowed between authenticated and known partners. Additional layers of security (e.g., firewalls, intrusion detection, etc.) could be implemented at a facility as needed.

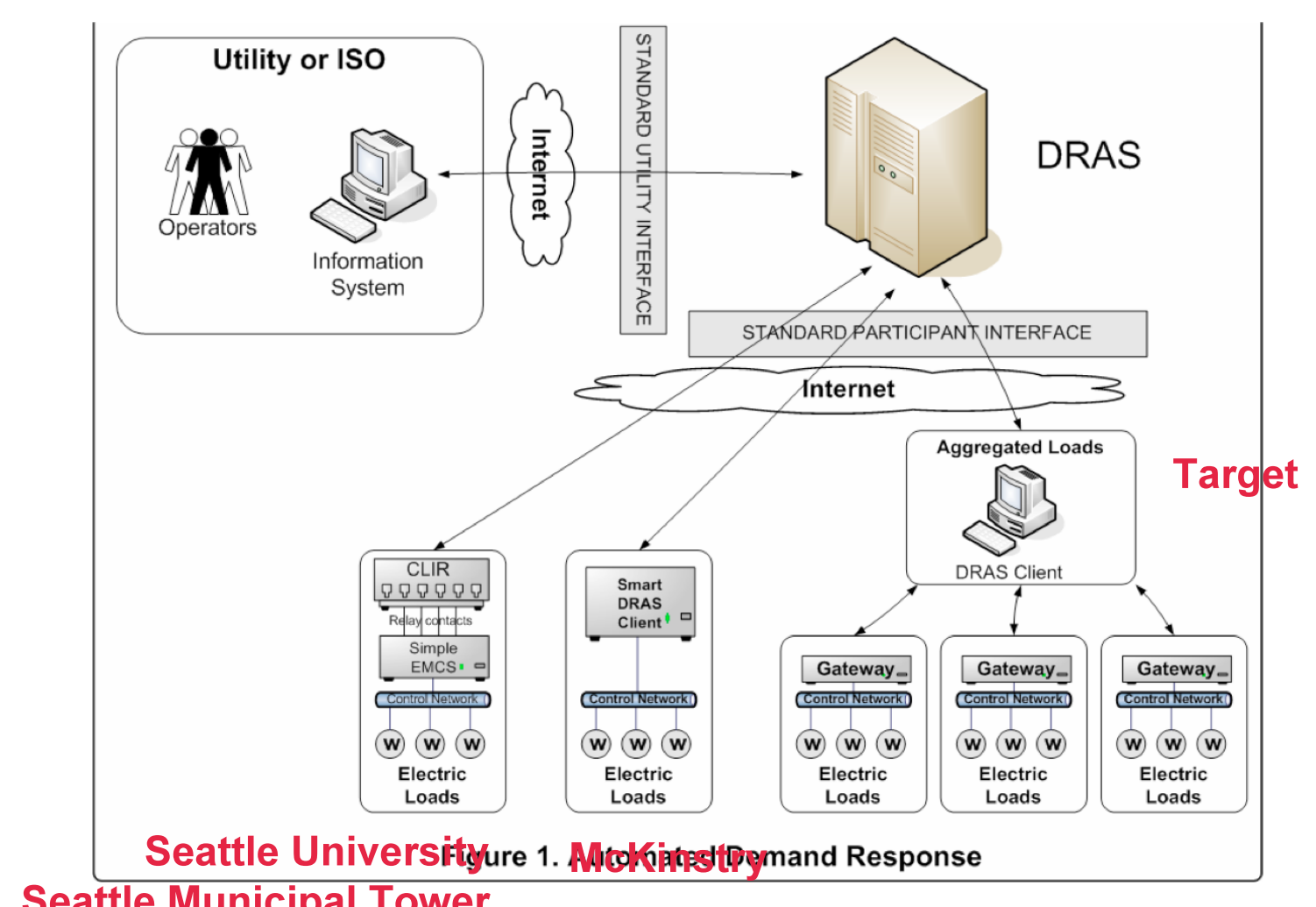

\section{Seattle Municipal Tower}

Figure 1. OpenADR architecture

1 shows the architecture and type of client utilized at each facility. Auto-DR using the OpenADR architecture shown in 1 consists of a DRAS that sends signals of DR events to customers and a DRAS client at the customer's site to receive DR signals and provide automation signals to existing pre-programmed controls. There are two types of DRAS clients:

1. CLIR or a simple client for legacy control systems - This device directly maps price-levels on to relay closures.

2. A web services software or smart client for sophisticated control systems - Multi-site enterprise control systems with embedded software clients are included in the smart client category. 
In this demonstration, two participants, Seattle University and SMT, used CLIR boxes to communicate with the DRAS. McKinstry has a Richards-Zeta Mediator TM gateway device. Richards-Zeta developed a software client that communicates with the DRAS and embedded this client into the Mediator ${ }^{\mathrm{TM}}$ located at McKinstry. Target developed a software client and embedded it into its enterprise control system in Minneapolis. ${ }^{3}$ This software client polled the DRAS every minute and sent the DR event information to Target stores' control equipment.

\section{The DR Automation Server}

Several enhancements were made to the DRAS for this project. This DRAS was built to the specifications published by Piette et al. (2009). Figure 2 displays the front page of the DRAS Web interface.

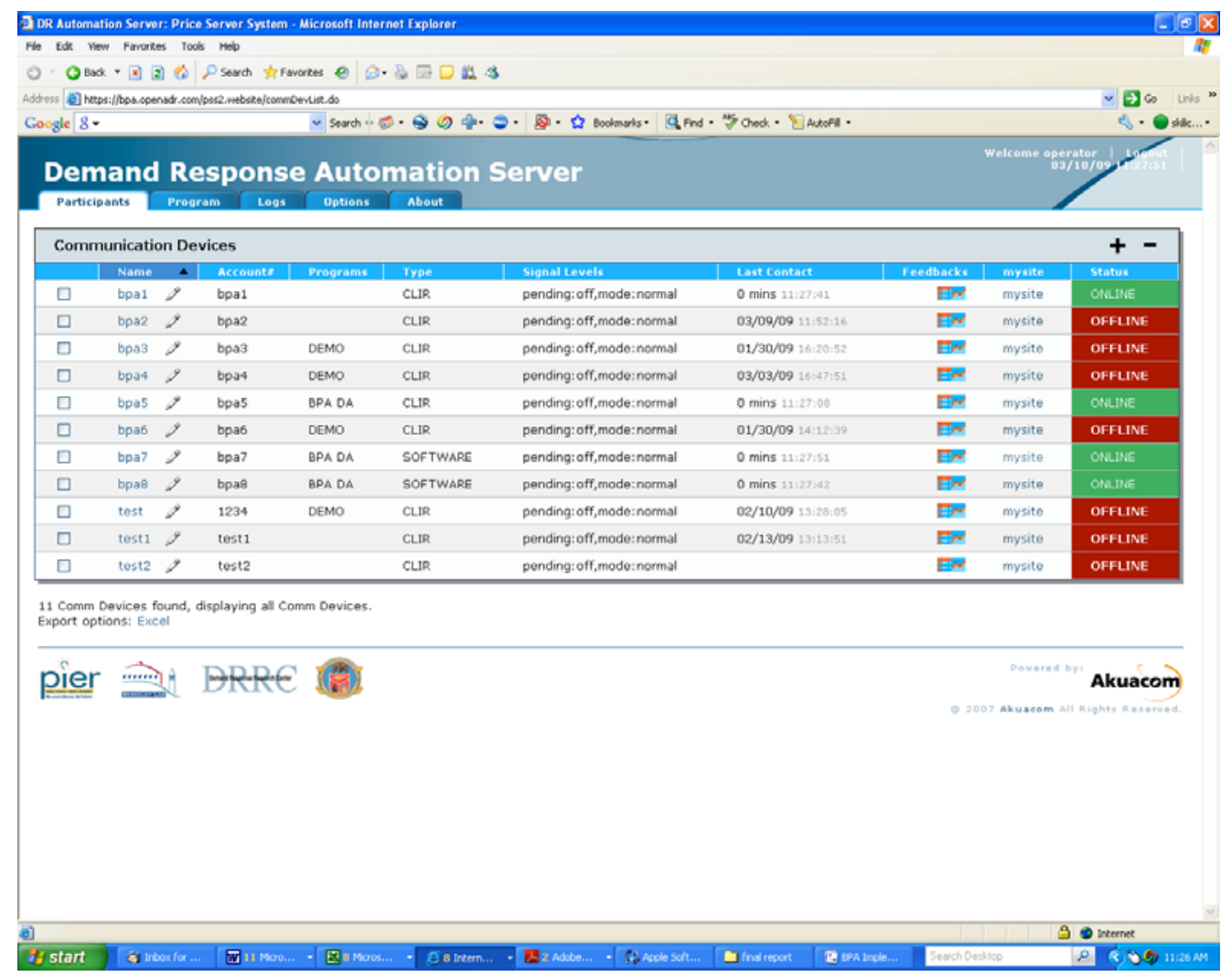

Figure 2. Demand response automation server (DRAS) web interface

The front page of the DRAS displays all the information necessary for a utility operator to monitor each DRAS client, including the DR program in which the DRAS client is participating, the type of DRAS client (CLIR vs. web service software), current DR event signals, the last contact with the client, a link to meter data, and an online portal to the client (which is called "mysite"). The link to each site's meter data, called "feedback," was not used in this project. The far right column shows whether the client is on line or off line. For these tests, each client was named "bpa" plus a number. The clients remained in the "DEMO" program until tests were complete and clients were assigned to either day-ahead or day-of events. The process of sending even signals hard-coded into the system so that signals were sent at the appropriate times. During events, pending is set to "on," and mode is set to "high."

${ }^{3}$ Target stores have centralized DR capability through the enterprise control system 


\section{Recruitment}

McKinstry recruited project participants. Given the short amount of time for recruiting and setting up participants, McKinstry targeted customers with EMCSs who were also already on SCL's MeterWatch meter data collection and monitoring system. McKinstry approached a total of 11 customers with a goal of recruiting three to five. Each was offered $\$ 3,000$ for setup to join the project and $\$ 1,000$ for participating in each event in the winter and $\$ 2,000$ for setup and $\$ 500$ for participating in each event in the summer. Although the summer incentives were smaller, all participants from the winter tests took part in the summer tests.

\section{Training}

LBNL conducted three training sessions. The first, for the project team, discussed the project plan and communication technology; McKinstry was also trained to install CLIR boxes. The second and third training sessions were designed for control vendors. These sessions covered DR strategies in detail and questions related to pre-programming and sustaining savings over longer DR periods. Most participating sites were set up for two adjustments to their energy consumption during a summer DR event. The first adjustment (DR strategy) was initiated when the event start signal was received, and a second adjustment (DR strategy) was initiated two hours into the DR event to sustain the demand reduction.

\section{Technical Steps Toward Customer Enablement}

Enabling DR automation at a customer's site involves establishing communications and preprogramming DR control strategies. The first step was to evaluate the customer's EMCS and determine whether the customer needed a hardware client or a software client. Hardware clients (CLIR boxes), which cost $\$ 1,500$, were provided at no cost. (Note that there are alternative OpenADR clients in the marketplace. $\left.{ }^{4}\right)$ A template was provided to the EMCS vendor to facilitate the development of the software clients.

While communication issues were being resolved, the sites were provided a prioritized list of DR strategies and asked to select the strategies they would like to implement. Considering the project timeline and budget, not all proposed DR strategies were implemented at each of the facilities.

As soon as communication was established, the DRAS operator was notified so that the communications could be verified from the DRAS operator screen. McKinstry could log into the facility's "mysite" page, which allows facility managers to change price proxies for DR events. The price proxy can be changed to "normal," "moderate," or "high," and the DR strategies can be tested as the price proxy is changed. Commissioning this system entailed changing the price proxy and observing that the EMCS responded with a corresponding strategy. Figure 3 displays the flow chart for the entire process and the documentation that was made available.

\footnotetext{
${ }^{4}$ Some of the alternatives are: Stonewater Gateway ${ }^{\mathrm{TM}}$, Honeywell Tridium ${ }^{\mathrm{TM}}$, Richards-Zeta Mediator ${ }^{\mathrm{TM}}$.
} 


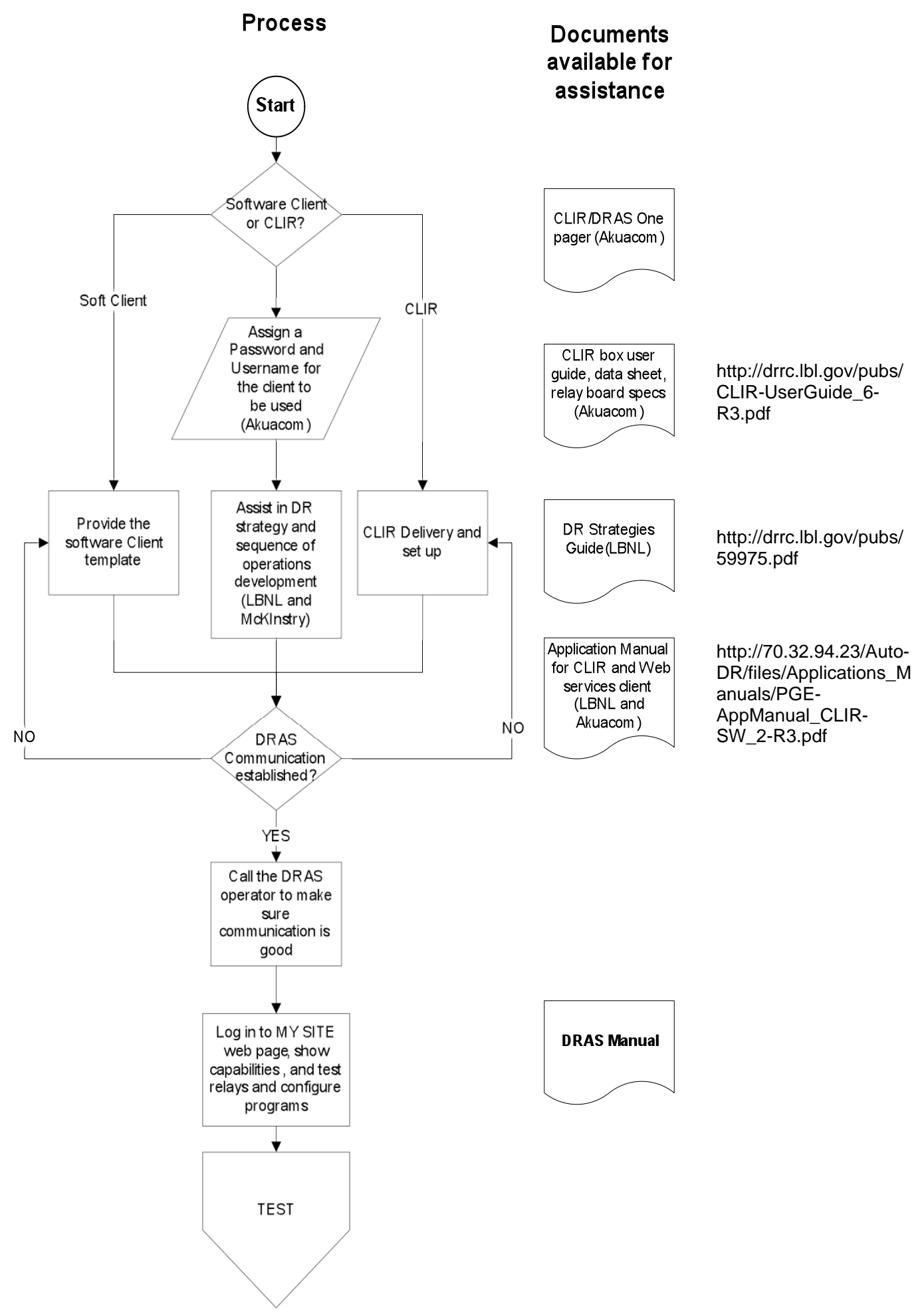

Figure 3. Flow chart of technical steps to enable customer participation 


\section{Testing and Commissioning Procedures}

Each installation was followed by commissioning, or manually triggering each price proxy to confirm the EMCS response. The "normal," "moderate," and "high" price proxies were tested, but not the "pending" signal. Pending signal testing was not available through the DRAS.

The untested pending signal, which was used at one site to trigger pre-heating during the winter tests, caused a major disruption during the summer events, sending the site into pre-heating mode on a hot summer morning before the DR event started. Occupants complained, and the DR event was terminated. The problem was identified, and the EMCS was reconfigured to check both the pending signal and the building operation mode before dispatching the appropriate DR strategy.

\section{Operations During Demand Response Events}

Throughout the project, Akuacom functioned as the DRAS operator, configuring the DRAS, issuing DR signals to facilities, and monitoring customer participation and performance during Auto-DR events. LBNL worked with Akuacom and McKinstry throughout the project to manage pre-DR event activities, operations during DR events, and the post-DR event process.

\section{Pre-DR Event Activities}

As the DRAS operator, Akuacom was responsible for daily monitoring of the DRAS and the site clients. When client communication was interrupted, the project team received automated notification, and, whenever a client was found to be off line, Akuacom notified LBNL and McKinstry and asked the team to investigate the problem.

There were no instances where an Auto-DR customer could not participate in a $D R$ event because of a problem with the DR Automation Server or client infrastructure.
LBNL called a total of 16 summer and winter DR events. Routine checking of the DRAS and client status along with the automated notifications when clients were offline meant that communication problems between the DRAS and clients or other issues related to client software/hardware were identified well in advance of DR events. There were no instances where an Auto-DR customer could not participate in a DR event because of a problem with the DRAS or client infrastructure.

\section{Operations During DR Events}

During a DR event, at least one DRAS operator was on duty throughout the entire day. The operator on duty was responsible for monitoring the DRAS and status of all clients at frequent intervals (approximately every half hour) to verify that:

1. there was no loss of communication between the DRAS and its clients;

2. if the client went offline, McKinstry and the customer were notified immediately so that the problem was resolved as soon as possible; and

3. the DRAS sent out the appropriate event pending and shed signals at the appropriate times.

\section{... the project team did not encounter any problems with the DR Automation Server or the communications during the $D R$ events.}

At the end of the DR events, the operator verified that the DRAS returned the status of each DRAS client to "normal" (no load-shed) mode. The project team did not encounter any problems with the DRAS or the communications during the DR events. 


\section{Post-DR Event Process}

LBNL was responsible for tracking each Auto-DR customer's load-shed performance. LBNL coordinated data collection with McKinstry. Target sent its data after each event. SMT's data were downloaded from MeterWatch. For the other sites, McKinstry had to send a person to download the meter data. Using each customer's historical and event day load data as well as outside air temperature data from the National Oceanic \& Atmospheric Administration, LBNL developed three baselines, as described in more detail below. At the end of each DR season, LBNL prepared a load-shed summary report for each customer that tracked the load shed relative to each of the three baseline methodologies for all of the DR events. LBNL and McKinstry also worked together to solicit feedback from all of the Auto-DR customers after each DR event. This post-event activity is described below following the descriptions of the baselines.

\section{Baseline Development}

The LBNL team developed baseline models to measure load-shed performance. The baselines estimate what the electrical load shape would have been if there had not been a DR event.

LBNL previously developed a number of baseline models to estimate the demand savings from DR strategies (Coughlin et al. 2008). Three baseline models were used here to calculate demand reductions for this project:

- outside air temperature regression (OATR) model,

- the "three-in-ten" (3/10) baseline model, and

- the "average of similar days" baseline model.

The OATR baseline model is the most accurate, least biased model among the three and works best for weather-sensitive buildings. However, collecting weather data from a site or a location close to a site is cumbersome; therefore, the $3 / 10$ baseline model, which uses average hourly load shape of the three highest energy-consuming days during the 10 work days preceding the DR event of interest, is the baseline model preferred by utilities in California. Developing the 3/10 baseline does not involve collecting weather data, which simplifies the development process. The average- of-similar-days model can be used when archived data are insufficient to develop the other two baselines (this was the case for the Target stores in this project).

The demand savings estimates for most of the buildings that participated in the study are based on the baseline OATR model. The exception is for the Target facilities, which did not have archived data, so, for the first site and the first events, the average-of-similar-days model was used based on as many non-DR days as were available. If the model predicts a lower baseline than the actual demand for any given 15-minute or hourly period, this indicates negative demand savings. Negative demand savings are often found after a DR period as part of a "rebound" or recovery peak in which the HVAC system tries to bring the thermal zones back to normal conditions.

The evaluations performed include quantifying the demand savings in kilowatts $(\mathrm{kW})$ at each site along with the savings in whole-building power reduction by percentage, and the demand intensity $\left(\mathrm{W} / \mathrm{ft}^{2}\right)$. The demand savings are calculated by subtracting the actual whole-building power from baseline demand. The demand savings percentage is defined as the percentage of savings in whole-building power. The demand-savings intensity $\left(\mathrm{W} / \mathrm{ft}^{2}\right)$ is the demand reduction (W) normalized by the building's conditioned floor area $\left(\mathrm{ft}^{2}\right)$. 
The LBNL model that was used to calculate the summer afternoon demand reductions uses OATR with a scalar adjustment for the morning load. This methodology was utilized for the summer tests. However, for the winter tests, because the morning periods are when the Seattle DR events took place, a morning adjustment component was replaced and tested with an afternoon adjustment component because the afternoon periods capture and represent internal loads.

The subsections below describe the three baseline models and the afternoon adjustment calculations.

\section{Outside air temperature regression model baseline}

Electricity consumption data for each site were collected either through meter data monitoring and logging equipment installed at each facility or through Seattle MeterWatch, a program that is available through SCL. The actual metered electric consumption was subtracted from the baseline-modeled demand to derive an estimate of demand savings for each 15-minute period. Previous research recommends a weather-sensitive baseline model with adjustments for morning load variations for accuracy (Goldberg and Agnew 2003).

For the OATR baseline, a whole-building power baseline was estimated first, using a regression model that assumes that whole-building power is linearly correlated with outside air temperature. The model is computed as shown in equation 1 ;

$L_{i}=a_{i}+b_{i} T_{i}$

where $L_{i}$ is the predicted 15-minute interval electricity demand for time $i$ from the previous non-DR event workdays. Depending on the time interval of the available weather data, $T_{i}$ is the hourly or 15-minute interval outside air temperature at time $i$. The parameters $a_{i}$ and $b_{i}$ are generated from a linear regression of the input data for time $i$. Individual regression equations are developed for each 15-minute interval, resulting in 96 regressions for the entire day (24 hours/day, with four 15minute periods per hour. Time $i$ is from 0:00 to 23:45). To develop the baseline electricity loads for determining demand savings, 20 "non-demand response" days were selected. These 20 baseline days were non-weekend, non-holiday, Monday through Friday workdays. The source of the temperature data was Boeing Field. Input data were 15-minute interval whole-building electricity demand and 15-minute interval or hourly outside air temperature.

\section{Three-in-ten (3/10) baseline}

California utilities use the $3 / 10$ baseline to estimate the baseline against which DR savings are calculated. The $3 / 10$ baseline is the average hourly load shape of the three highest energyconsuming days during the most recent 10 work days (excluding holidays). The baseline algorithm for this project considers the site electricity
A disadvantage of the $3 / 10$ baseline method is that it may calculate a baseline that is lower than the actual demand if the site's demand is weather sensitive and the weather temperatures were mild prior to the DR event day. consumption from 7 a.m. to 10 a.m. for the winter and noon to $5 \mathrm{pm}$ in the summer when selecting the three days of highest consumption prior to a DR event. DR event days are excluded from the reference days. A disadvantage of the $3 / 10$ baseline method is that it may calculate a baseline that is lower than actual demand if the site's demand is weather sensitive and the weather temperatures were mild during the period prior to the DR event day. This can occur if a DR event is called on a day with more extreme outside temperatures than during the previous 10 days. When cooling loads are shed for DR (typically done in warm climates), baseline demand curves can be biased low if the previous 10 working days were cooler than the DR event day. The (low) bias problem can also occur for estimates related to winter tests when heating loads are shed for DR as was done for this test because the previous 10 days were likely to be warmer than the day 
of the DR event. For commercial buildings, the OATR baseline is a more accurate and less biased baseline than the $3 / 10$ baseline (Coughlin et al. 2008).

As an example, SMT's participation in the March 3 DR event is displayed in Figure 4. The chart shows the actual whole-building power, the LBNL OATR baseline (indicated as "baseline"), and the $3 / 10$ baseline. These baselines estimate what the whole-building power would have been if the DR event had not occurred. The vertical line at each baseline power data point is the standard error of the regression estimate. The vertical lines at 7 a.m. and $10 \mathrm{a} . \mathrm{m}$. identify the DR event period. On this day, the $3 / 10$ baseline is higher than the OATR baseline because there were cooler days during the previous 10 days that were used to develop the baseline. An OATR baseline with adjustments (OAT_A) might be more accurate. In an OAT_A baseline, an adjustment factor $\left(r_{a}\right)$ is multiplied by each 15-minute load. The factor $r_{a}$ is defined as the ratio of the actual to the predicted load during the four hours in the afternoon preceding the winter DR event and four hours in the morning prior to the summer DR event, as shown in Equation 2.

$r_{a}=\sum_{i=1}^{n} L_{a, i} / \sum_{i=1}^{n} L_{p, i}$

Where $r_{a}$ is the adjustment factor,

$L_{a, i}$ is the actual hourly average load on DR day at the hour's start at $i p m$,

$L_{p, i}$ is the predicted load by baseline at the hour's start at $i p m$., and

$n$ is the number of hours which are used for adjustment ( $n=4$ for this analysis).

Seattle Municipal Tower, 3/3/2009 (Min OAT: $43^{\circ} \mathrm{F}$ )

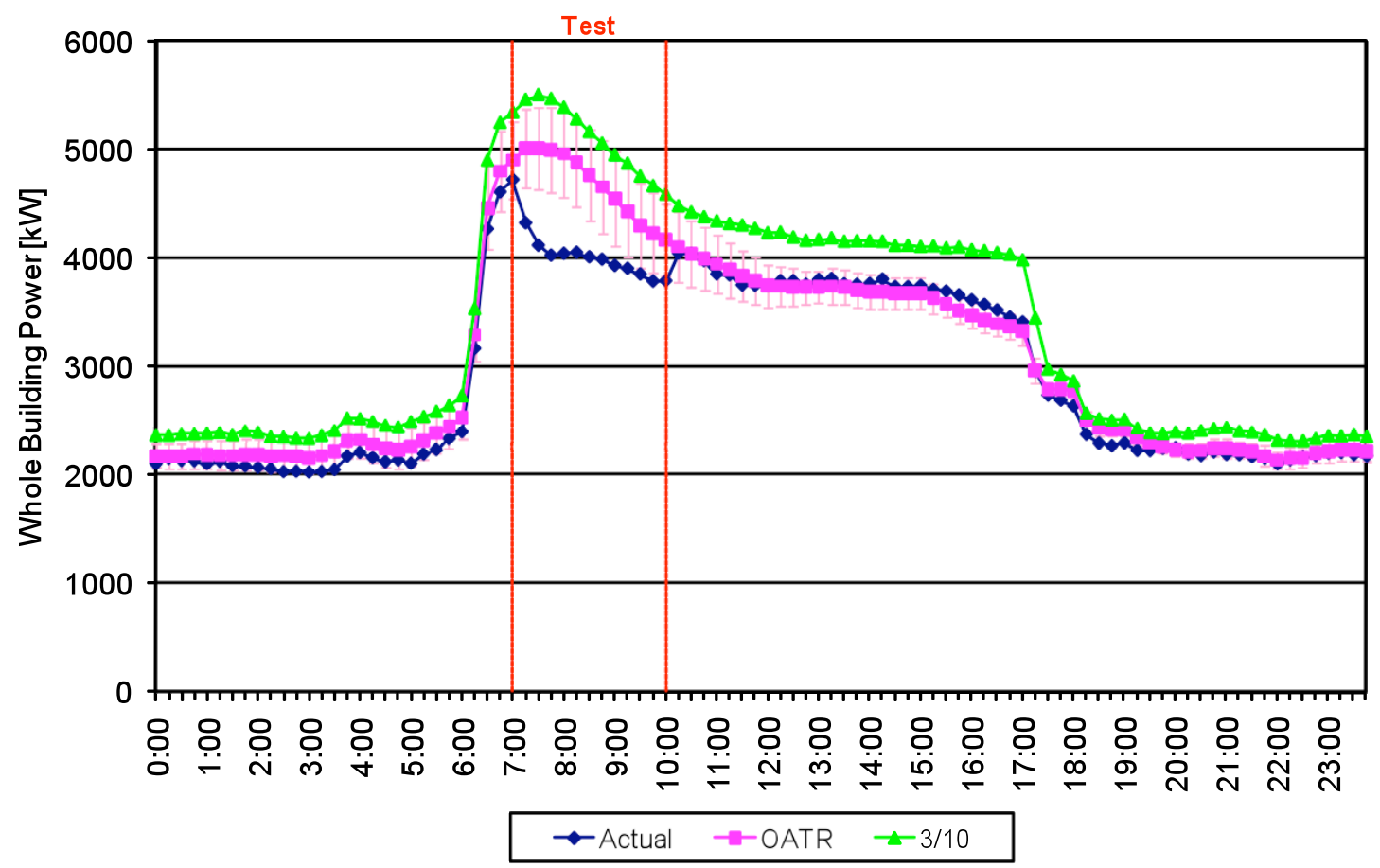

Figure 4. Whole building demand profile 
B O N N E V I L L E

\section{Average-of-similar-day baseline}

For two of the Target sites whose interval meters were installed two days before the test events, the average-of-similar-day baseline was used because of the lack of prior data. For these sites, available data were averaged to develop the baseline. As the events progressed, the average used to develop the baseline included non-test days. 


\section{Summary of OpenADR Technology Performance}

As of the end of November 2009, four DRAS clients were operational for the project: two CLIR boxes and two software clients. One of the software clients was embedded in a Richards-Zeta Mediator ${ }^{\mathrm{TM}}$, and the other was embedded in the Target's Automated Logic Corporation (ALC) WebCTRL TM enterprise EMCS. The DRAS was running and available $100 \%$ of the time during the test. No outages were experienced during either the winter season or the summer season. The CLIR and the software clients exceeded $99.99 \%$ reliability once the initial installation and integration were complete.

There were two minor communication-related problems during the project. One of these was a malfunctioning CLIR box (username bpa2), which had been damaged during shipment. The box was replaced when communication could not be established. The other problem resulted from a change in the information technology (IT) setup at Seattle University, and the CLIR box was not brought on line by the IT department until the final IT configurations were completed. The delay in that case meant that the site had to trigger events manually until the last event. Thus, the last event called during the summer was the only event that was fully automated at Seattle University.

\section{Building Systems and DR Strategies}

During previous studies in California that addressed summer afternoon peak demand, the global temperature adjustment (GTA) strategy had been found to be effective and one of the least disruptive DR strategies (Motegi et al. 2007). This strategy effectively pre-cooled the buildings prior to an event so that use of air conditioning during the event was not needed. To develop heating DR strategies for this project the team had to study the client heating systems in detail.

If the building systems used gas for heating, the only potential savings from GTA would be the savings from fan power in variable air volume (VAV) systems. When the heating set point is reduced, the fans that supply heat to a zone will temporarily slow down, which reduces electricity demand. Of the five buildings that participated in the OpenADR events, two Target stores with gas heating roof-top units (RTUs), participated using both lighting and HVAC system strategies.

SMT has an all-electric heating system and chillers for cooling and employed GTA both winter and summer with pre-heating and pre-cooling, respectively. Seattle University, which receives steam and chilled water from the campus, selected preheating as a winter strategy. To do this, they turned off electrical heating units and adjusted temperature set points to reduce demand from the campus supply. McKinstry duty-cycled RTUs in the winter, adjusted temperature set points, and reduced lighting in the kitchen area. A detailed description of the DR strategies for each site appear below, after Tables 1 and 2. The HVAC and lighting systems in each of the facilities are summarized in Table 1.

Table 1. Description of HVAC and lighting systems

\begin{tabular}{|l|l|l|l|}
\hline \multicolumn{2}{|l|}{ HVAC System } & Lighting System \\
\hline Site & Primary System Attributes & Secondary System Attributes & Switching/Dimming \\
\hline McKinstry (McK) & $\begin{array}{l}\text { Gas heating combination of } \\
\text { VAV (7) and CAV (16) RTUs } \\
\text { (total - 23) }\end{array}$ & $\begin{array}{l}\text { Single duct; 10 single zone, 13 } \\
\text { multi-zone }\end{array}$ & $\begin{array}{l}\text { Central Scheduled } \\
\text { Sweep }\end{array}$ \\
\hline Seattle Municipal Tower (SMT) & $\begin{array}{l}\text { Electric heating VAV } \\
(690) \text { with AHUs (48) }\end{array}$ & Single duct; multi-zone & $\begin{array}{l}\text { Central Scheduled } \\
\text { Sweep }\end{array}$ \\
\hline Target (both stores) & Gas heating VAV RTU (15) & Single duct; single zone & $\begin{array}{l}\text { Central fixture } \\
\text { swichting (checker } \\
\text { board) }\end{array}$ \\
\hline Seattle University (SU) & $\begin{array}{l}\text { Electric heating; VAV (102) } \\
\text { with AHUs (4), cabinet and } \\
\text { unit heaters }\end{array}$ & $\begin{array}{l}\text { Single duct; multi-zone; with } \\
\text { reheat }\end{array}$ & $\begin{array}{l}\text { Central Scheduled } \\
\text { Sweep }\end{array}$ \\
\hline
\end{tabular}


Table 2 summarizes each participant's summer and winter peak demand. The largest buildings are SMT and Target T0637. Seattle University has significantly lower summer demand intensity because the facility receives chilled water from the campus.

Table 2. Participants' summer and winter peak demand from the electric meter

\begin{tabular}{|c|c|c|c|c|}
\hline \multirow{2}{*}{ Site Peak } & \multicolumn{2}{|c|}{ Summer } & \multicolumn{2}{c|}{ Winter } \\
\cline { 2 - 5 } & W/sqft & kW & W/sqft & kW \\
\hline \hline McKinstry & 5.22 & 522 & 3.47 & 347 \\
\hline Seattle Municipal Tower & 4.10 & 4921 & 5.14 & 6168 \\
\hline Seattle University & 1.76 & 176 & 8.42 & 841 \\
\hline Target - T1284 & 4.73 & 784 & 3.22 & 534 \\
\hline Target - T0637 & 3.22 & 320 & - & - \\
\hline
\end{tabular}

A detailed description of the DR strategies used for each site is as follows:

- Target (both stores):

- Winter DR Strategy: Turn off $50 \%$ of sales area lights, turn off two out of 12 RTUs, and decrease temperature set points by $2^{\circ} \mathrm{F}$.

- Summer DR Strategy: Turn off $50 \%$ of sales area lights, turn off two out of 12 RTUs, and increase temperature set points by $2^{\circ} \mathrm{F}$ for the first two hours and an additional $2{ }^{\circ} \mathrm{F}$ for the remaining three hours.

- Recovery: No known recovery strategy.

- Issues: Stores did not have interval meters so meters had to be installed.

- Seattle Municipal Tower

- Winter DR Strategy: Decrease set points from $72^{\circ} \mathrm{F}$ to $68^{\circ} \mathrm{F}$ on 24 of 62 floors. Cycle VAV boxes (690) and corresponding air handling units (48).

- Summer DR Strategy: Raise set points to $76{ }^{\circ} \mathrm{F}$ when event starts. Two hours into event, raise set points to $78^{\circ} \mathrm{F}$. Go to unoccupied mode at end of event.

- Recovery: Set back set points by $1^{\circ} \mathrm{F}$ every 15 minutes and bring one-quarter of equipment back on line every five minutes.

- Issues: The site only completed the DR strategy programming on 26 out of 62 floors because of time limitations.

\section{- McKinstry}

- Winter DR Strategy: Uniformly turn off half of the 23 RTUs for 15 minutes; alternate with the remaining units every 15 minutes.

- Summer DR Strategies: Pre-cool by $2^{\circ} \mathrm{F}$ two hours before DR event. Raise set points by $2 \stackrel{\circ}{\circ}$ when event starts. Two hours into the event, raise set points by additional $2 \stackrel{\circ}{\circ} \mathrm{F}$ for the remaining DR period. Dim lights in deli and commons to $50 \%$ first two hours, and dim kitchen lights by $50 \%$ at 3 p.m. Building goes to unoccupied mode after the event. 
- Recovery: Stage turning on equipment every two minutes.

- Issues: This site was not connected to SCL's MeterWatch utility information system.

\section{- Seattle University}

- Winter DR Strategy: At 5 a.m., pre-heat to $74^{\circ} \mathrm{F}$ (only on day-ahead event days because pending signal for day-of events are not received until 6 a.m.) Decrease set point to $68^{\circ} \mathrm{F}$. Cycle cabinet heaters (7) and unit heaters (2) 20 minutes every 30 minutes. Cycle through half of VAV/Air terminal boxes (75) and air handling unit fans (4) every half hour. Increase carbon dioxide set point by 200 parts per million. Turn off hot water panel radiator.

- Summer DR Strategies: Pre-cool $2{ }^{\circ} \mathrm{F}$ two hours before event. Reset temperature set points by $3^{\circ} \mathrm{F}$ when event starts and an additional $3^{\circ} \mathrm{F}$ two hours into the event.

- Recovery: Return set points to original levels (maximum rate of set point change is $1^{\circ}$ per 15 minutes) and turn half of units on; five minutes later, turn remainder of units on.

- Issues: This site did not have an interval meter. A logger was installed for the duration of the project.

Error! Reference source not found. displays a range of DR strategies that were discussed with the sites and summarizes the DR strategies chosen by each site

\section{Table 3. Summary of DR control strategies}

\begin{tabular}{|c|c|c|c|c|c|c|c|c|c|c|c|c|c|c|c|c|c|c|c|c|c|}
\hline & \multicolumn{13}{|c|}{ HVAC } & \multicolumn{5}{|c|}{ Lighting } & \multicolumn{3}{|c|}{ Other } \\
\hline Site & 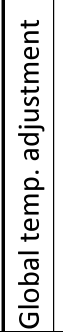 & 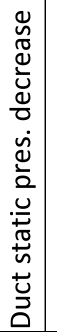 & 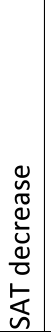 & 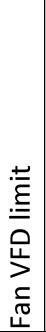 & 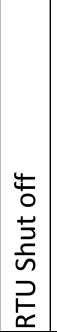 & 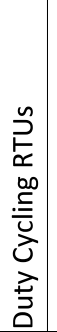 & 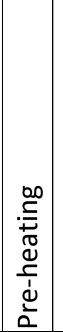 & 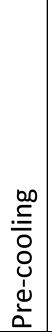 & 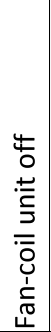 & 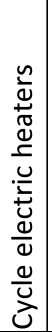 & 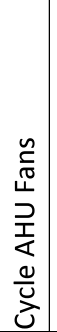 & $\begin{array}{c}\frac{n}{3} \\
\frac{\Delta}{U} \\
\frac{U}{J}\end{array}$ & 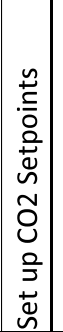 & 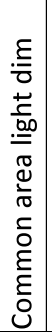 & 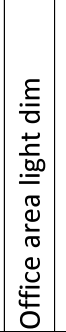 & 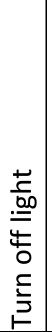 & 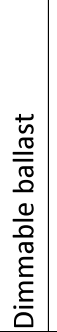 & 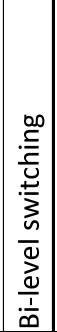 & 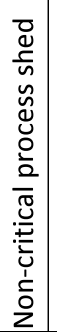 & 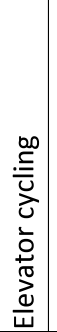 & 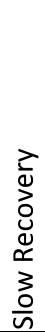 \\
\hline McKinstry & $\mathrm{S}$ & & & & & $\mathrm{W}$ & & $\mathrm{S}$ & & & & & & & & $\mathrm{S}$ & & & & & W \\
\hline Target - T1284 & ws & & & & WS & & & & & & & & & & & & & WS & & & \\
\hline Seattle Municiple Tower & WS & & & & & & & & & & $W$ & W & & & & & & & & & WS \\
\hline Seattle University & ws & & & & & $\mathrm{W}$ & W & $\mathrm{S}$ & & $\mathrm{W}$ & W & $\mathrm{W}$ & W & & & & & & & & W \\
\hline
\end{tabular}

Highlighted cells indicate selected strategy. $\mathrm{W}=$ winter strategy; $\mathrm{S}=$ summer strategy

\section{Costs}

Table 4 summarizes costs of enabling OpenADR in participating facilities. Highlighted rows indicate winter costs. The data were collected from invoices that were submitted by each facility. Controls costs are for pre-programming DR strategies into the EMCS. These are expected to be lower if the winter and summer DR strategies are pre-programmed at the same time. The increase in costs at two facilities for summer DR strategies is due to the inclusion of trend logging in the second phase of the project. Some sites already had trend logs set up; those sites had no additional costs. Material costs include wires and additional control devices. Target conducted its own commissioning, at no cost to the project, so the two Target facilities' information indicates no additional commissioning costs. 
Table 4. Costs of enablement

\begin{tabular}{|c|c|c|c|c|c|c|c|c|c|c|c|c|}
\hline \multirow{3}{*}{$\begin{array}{r}\text { Site } \\
\text { McKinstry }\end{array}$} & \multirow{3}{*}{$\begin{array}{l}\text { Controls } \\
\text { Vendor }\end{array}$} & \multicolumn{2}{|c|}{$\begin{array}{c}\text { Controls } \\
\text { Cost }\end{array}$} & \multicolumn{2}{|c|}{ Material } & \multicolumn{2}{|c|}{$\begin{array}{l}\text { Electrical } \\
\text { Labor }\end{array}$} & \multicolumn{2}{|c|}{$\begin{array}{c}\text { Commissioning } \\
\text { DR Strategies }\end{array}$} & \multicolumn{2}{|c|}{ Total } & \multirow{2}{*}{$\begin{array}{c}\begin{array}{c}\text { Total } \\
(\mathbf{\$} / \mathbf{k W})\end{array} \\
282\end{array}$} \\
\hline & & $\$$ & 3,780 & $\$$ & 1,064 & $\$$ & 1,005 & $\$$ & 1,071 & $\$$ & 5,915 & \\
\hline & & $\$$ & 2,470 & $\$$ & 200 & $\$$ & 609 & $\$$ & 1,530 & $\$$ & 4,200 & 105 \\
\hline \multirow{2}{*}{$\begin{array}{l}\text { Seattle Municipal } \\
\text { Tower }\end{array}$} & \multirow[b]{2}{*}{ Siemens } & $\$$ & 4,007 & $\$$ & 1,500 & $\$$ & 1,005 & $\$$ & 1,071 & $\$$ & 6,578 & 13 \\
\hline & & $\$$ & 6,800 & $\$$ & - & $\$$ & - & $\$$ & 1,530 & $\$$ & 8,330 & 46 \\
\hline \multirow{2}{*}{ Target (both stores) } & \multirow[b]{2}{*}{ ALC } & $\$$ & 6,500 & $\$$ & 1,582 & $\$$ & 2,000 & $\$$ & - & $\$$ & 8,082 & 40 \\
\hline & & $\$$ & 2,850 & $\$$ & - & $\$$ & - & $\$$ & - & $\$$ & 2,850 & 10 \\
\hline \multirow{2}{*}{ Seattle University } & \multirow[b]{2}{*}{ ESC } & $\$$ & 2,783 & $\$$ & 1,000 & $\$$ & 1,005 & $\$$ & 1,071 & $\$$ & 4,854 & 40 \\
\hline & & $\$$ & 6,975 & $\$$ & 927 & $\$$ & 2,438 & $\$$ & 1,530 & $\$$ & 9,432 & 269 \\
\hline
\end{tabular}

Highlighted rows indicate winter costs. 


\section{Demand Response Event Results}

This section describes event days and conditions and presents examples of aggregate savings from winter and summer DR events and best- and worst-performing dates for each site in each season.

\section{Summary of Event Days and Conditions}

A total of 16 DR events were dispatched based on outside air temperature forecasts in 2009. Error! Reference source not found.summarizes the DR event days, participation, and outside air temperatures. The first column shows the day of the week on which the site participated in the DR event. The second column shows the date of the event. If a site participated in the event, the cell associated with the date and site is highlighted, and the colors signify whether the event was day-ahead (blue) or day-of (yellow). The project team wanted to ensure that each site participated in three day-ahead events and one day-of event each season. The last column displays the minimum outside air temperature during the DR period in the winter and the maximum outside air temperature during the DR period in the summer.

Table 5. Summary of OpenADR winter and summer DR events in 2009

\begin{tabular}{|c|c|c|c|c|c|c|c|c|}
\hline Day of Week & Date & Site & Seattle & $\begin{array}{c}\text { Target - } \\
\text { Northgate }\end{array}$ & Target - 2 & $\begin{array}{c}\text { Seattle } \\
\text { Municipal } \\
\text { Tower }\end{array}$ & $\begin{array}{c}\text { Seattle } \\
\text { Univ. }\end{array}$ & $\begin{array}{c}\text { Outside Air } \\
\text { Temp } \\
\text { (DegF) }\end{array}$ \\
\hline \hline Wed & 18-Feb & Test 1 & Yes & No & No & No & No & 34 \\
\hline Tues & 24-Feb & Test 2 & Yes & No & No & No & No & 34 \\
\hline Tues & 3-Mar & Test 4 & No & Yes & No & Yes & No & 43 \\
\hline Thur & 5-Mar & Test 5 & Yes & Yes & No & Yes & No & 36 \\
\hline Mon & 9-Mar & Test 6 & No & Yes & No & Yes & No & 33 \\
\hline Tues & 10-Mar & Test 7 & No & No & No & No & Yes & 28 \\
\hline Wed & 11-Mar & Test 8 & Yes & Yes & Yes & Yes & No & 28 \\
\hline Thurs & 12-Mar & Test 9 & No & No & No & No & Yes & 31 \\
\hline Mon & 16-Mar & Test 10 & No & No & Yes & No & Yes & 37 \\
\hline Wed & 18-Mar & Test 11 & No & No & Yes & No & Yes & 39 \\
\hline Fri & 20-Mar & Test 12 & No & No & Yes & No & No & 38 \\
\hline Wed & 19-Aug & Test 1 & Yes & Yes & Yes & Yes & No & 86 \\
\hline Thur & 27-Aug & Test 2 & Yes & Yes & Yes & Yes & No & 88 \\
\hline Fri & $11-S e p$ & Test 4 & No & Yes & Yes & Yes & No & 83 \\
\hline Tue & 15-Sep & Test 5 & No & Yes & Yes & Yes & No & 78 \\
\hline Tue & 22-Sep & Test 6 & Yes & No & No & No & Yes & 88 \\
\hline
\end{tabular}

Blue highlight indicates day-ahead notification of DR event; yellow highlight indicates day-of DR event notification .

\section{Summary of Winter Results}

The work described here is the first time OpenADR was employed to enable winter DR. Although Seattle's temperature swings between summer and winter are not extreme, it is a heatingdominant climate, and electric heating is widely used.

Figure 5 displays the average percent demand reduction at each of the facilities using the OATR baseline for all the sites except for Target, for which the averaging baseline was used because the Target DR tests started two days after the meter was installed, so there was no prior baseline. On average, the buildings that participated in the winter study delivered $14 \%$ demand reduction or $0.59 \mathrm{~W} / \mathrm{ft}^{2}$ over three hours. The best-performing winter site was Target [T1284], which consistently delivered $19 \%$ demand reduction. 


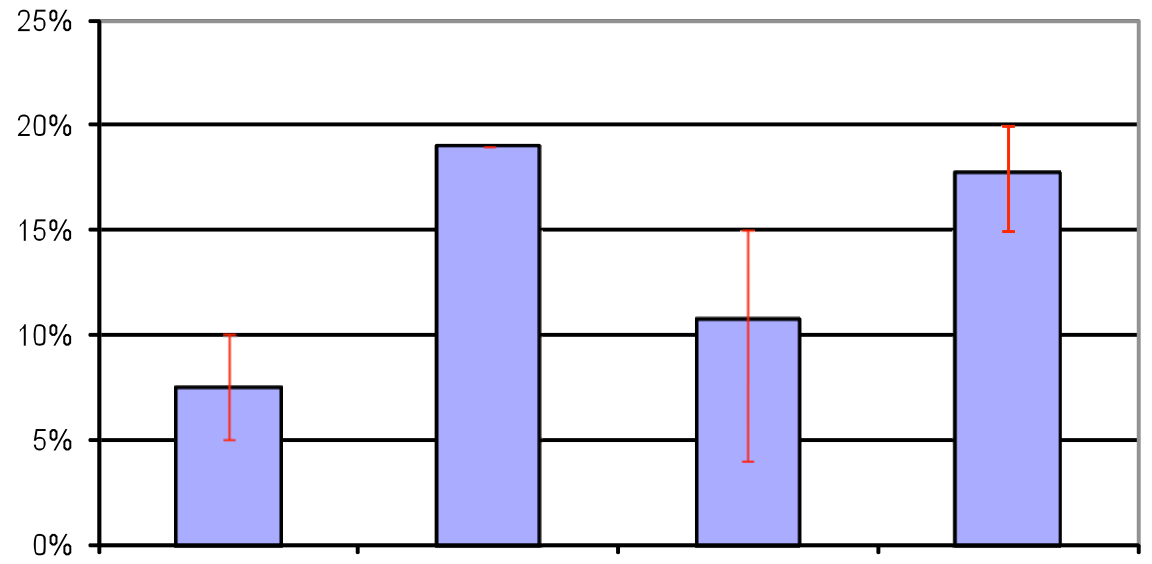

*Target result calculated using averaging baseline; all others use OATR baseline.

Figure 5. Average, minimum, and maximum demand reduction at each facility during the winter DR events

During the winter DR events, the sites delivered, on average, $767 \mathrm{~kW}$ demand reduction, which is $14 \%$ of the peak load (Table 6 ). The reductions resulted from demand shedding. Because loads were not deferred to other times of the day, 8.6 megawatt hours of energy were saved during the winter DR events.

Table 6. Summary of winter OpenADR tests

\begin{tabular}{|c|c|c|c|c|c|c|}
\hline Site & Test & Test 1 & Test 2 & Test 3 & Test 4 & Average \\
\hline \multirow[b]{3}{*}{ McKinstry } & W/sqft & 0.25 & 0.16 & 0.15 & 0.27 & 0.21 \\
\hline & $\mathrm{kW}$ & 25 & 16 & 15 & 27 & 21 \\
\hline & WBP\% & $9 \%$ & $6 \%$ & $5 \%$ & $10 \%$ & $8 \%$ \\
\hline \multirow{3}{*}{$\begin{array}{l}\text { Target - } \\
\text { T1284 }\end{array}$} & W/sqft & 0.50 & & 0.51 & & 0.51 \\
\hline & $\mathrm{kW}$ & 102 & & 104 & & 103 \\
\hline & WBP\% & $19 \%$ & & $19 \%$ & & $19 \%$ \\
\hline \multirow{3}{*}{\begin{tabular}{|l} 
Seattle \\
Municipal \\
Tower
\end{tabular}} & W/sqft & 0.57 & 0.60 & 0.18 & 0.40 & 0.44 \\
\hline & $\mathrm{kW}$ & 678 & 717 & 220 & 477 & 523 \\
\hline & WBP\% & $15 \%$ & $15 \%$ & $4 \%$ & $9 \%$ & $11 \%$ \\
\hline \multirow{3}{*}{$\begin{array}{l}\text { Seattle } \\
\text { University }\end{array}$} & W/sqft & 1.41 & 1.02 & 1.27 & 1.12 & 1.21 \\
\hline & $\mathrm{kW}$ & 141 & 102 & 127 & 112 & 121 \\
\hline & WBP\% & $20 \%$ & $15 \%$ & $19 \%$ & $17 \%$ & $18 \%$ \\
\hline \multirow[b]{3}{*}{ All Sites } & W/sqft & & & \multirow{3}{*}{\multicolumn{2}{|c|}{\begin{tabular}{|l|} 
Average $^{\star *}$ \\
Total $^{*}$ \\
Average $^{\star *}$
\end{tabular}}} & $\overline{0.59}$ \\
\hline & $\mathrm{kW}$ & & & & & 767 \\
\hline & WBP\% & & & & & $14 \%$ \\
\hline
\end{tabular}

During the winter DR tests, events were dispatched next day following the enablement of each site to capture cold winter morning responses. There was no single event in which all the sites 
participated. However, on March 11, four out of five sites participated in an event. The minimum outside air temperature during the DR period was $28^{\circ} \mathrm{F}$. Because of a communication issue, data for two sites could not be collected on this date. Figure 6 shows the only aggregated demand savings during the winter tests, for the March 5 event the only event in which all sites participated). Table 7 shows the maximum and average demand reduction of the aggregate savings for each hour as well as the DR period using both the outside air temperature baseline and the $3 / 10$ baseline. Average demand reduction per event of $767 \mathrm{~kW}$ (or 14\%) was recorded using the outside air temperature baseline on March 5 (Table 7). This value is calculated by averaging the sum of each test day. The majority of savings results from the large peak demand savings at SMT. In aggregate calculations, the largest load typically dominates the aggregate shape. SMT has the highest loads among the project sites; thus, its load shape dominates the aggregate shape. This load shape is also representative of the winter morning peak problem in Seattle.

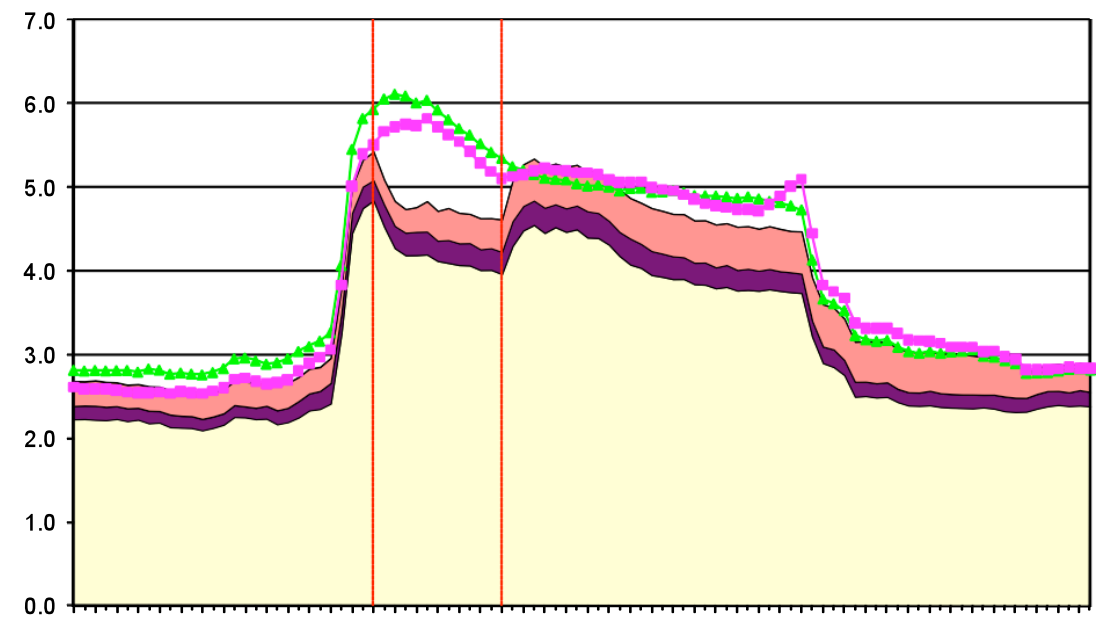

\begin{tabular}{|lllll|}
\hline$\square$ & $\square$ & $\square$ & - & - \\
\hline
\end{tabular}

Figure 6. Aggregate results from the DR event on March 5, 2009

Table 7. Summary of demand reduction on March 5, 2009

\begin{tabular}{|c|c|r|r|r|r|r|r|}
\hline \multirow{2}{*}{ Baseline } & \multirow{2}{*}{ Period } & \multicolumn{2}{|c|}{ kW } & \multicolumn{2}{|c|}{ W/ft $^{2}$} & \multicolumn{2}{|c|}{ WBP\% } \\
\cline { 3 - 8 } & & \multicolumn{1}{|c|}{ Max } & Ave & Max & Ave & Max & Ave \\
\hline \multirow{3}{*}{ OATR } & $\mathbf{7 : 0 0 - 8 : 0 0}$ & 1014 & 865 & 0.69 & 0.59 & $18 \%$ & $15 \%$ \\
\cline { 2 - 8 } & $\mathbf{8 : 0 0 - 9 : 0 0}$ & 1002 & 929 & 0.68 & 0.63 & $17 \%$ & $16 \%$ \\
\cline { 2 - 8 } & $\mathbf{9 : 0 0 - 1 0 : 0 0}$ & 742 & 613 & 0.51 & 0.42 & $13 \%$ & $11 \%$ \\
\cline { 2 - 8 } & $\mathbf{7 : 0 0 - 1 0 : 0 0}$ & 1014 & 802 & 0.69 & 0.55 & $18 \%$ & $14 \%$ \\
\hline \multirow{3}{*}{3110} & $\mathbf{7 : 0 0 - 8 : 0 0}$ & 1348 & 1206 & 0.92 & 0.82 & $22 \%$ & $20 \%$ \\
\cline { 2 - 8 } & $\mathbf{8 : 0 0 - 9 : 0 0}$ & 1202 & 1115 & 0.82 & 0.76 & $20 \%$ & $19 \%$ \\
\cline { 2 - 8 } & $\mathbf{9 : 0 0 - 1 0 : 0 0}$ & 941 & 836 & 0.64 & 0.57 & $17 \%$ & $15 \%$ \\
\cline { 2 - 8 } & $\mathbf{7 : 0 0 - 1 0 : 0 0}$ & 1348 & 1052 & 0.92 & 0.72 & $22 \%$ & $18 \%$ \\
\hline
\end{tabular}




\section{Summary of Summer Results}

The summer OpenADR test was better coordinated than the winter tests, so the sites participated in more events together. Therefore, more aggregated summer event results were calculated. The duration of summer DR events was increased to five hours as requested by the SCL operators. The summer study delivered, on average (i.e., average of each site's average), $16 \%$ demand reduction or $0.47 \mathrm{~W} / \mathrm{ft}^{2}$ over five hours with a cumulative energy savings of 6.5 megawatt hours.

Table 8 summarizes the performance of each of the sites during these events. The average percent demand reduction at each of the facilities was calculated using the OATR baseline with adjustment for SMT, Seattle University, and Target T1284. For Target T0637, the calculation used an averaging baseline with morning adjustment. For McKinstry, we used the OATR baseline without the morning adjustment because we used pre-cooling as a DR strategy at this facility. Another facility that also practiced two-hour pre-cooling is Seattle University. Historical data for this site are lacking, so we are unable to calculate the OATR baseline, and the averaging baseline falls much below the measured data. Therefore, we used an evening adjustment calculated over four hours.

The result is shown in Figure 7. The red bars show the minimum and maximum demand reduction during the summer DR events for that facility. The best performing sites were the two Target sites with average demand reduction of $28 \%$ and $19 \%$, respectively. Target's success can be attributed to the many summer DR tests they have conducted over the years in their facilities around the country.

Table 8. Summary of summer OpenADR tests

\begin{tabular}{|c|c|c|c|c|c|c|c|}
\hline Site & Test Date & Test 1 & Test 2 & Test 3 & Test 4 & Test 5 & Average \\
\hline \multirow[b]{3}{*}{ McKinstry } & W/sqft & 0.08 & 0.40 & 0.79 & $\begin{array}{ll}0.51 \\
\end{array}$ & $\begin{array}{l}0.50 \\
\end{array}$ & $\begin{array}{ll}0.46 \\
\end{array}$ \\
\hline & $\mathrm{kW}$ & 8 & 40 & 79 & 51 & 50 & 46 \\
\hline & WBP\% & $2 \%$ & $10 \%$ & $21 \%$ & $14 \%$ & $13 \%$ & $12 \%$ \\
\hline \multirow[b]{3}{*}{ Target - T1284* } & W/sqft & 1.24 & 0.71 & 1.72 & 0.57 & & 1.06 \\
\hline & $\mathrm{kW}$ & 205 & 118 & 284 & 94 & & 175 \\
\hline & WBP\% & $31 \%$ & $22 \%$ & $40 \%$ & $19 \%$ & & $28 \%$ \\
\hline \multirow[b]{3}{*}{ Target - T0637* } & W/sqft & 0.65 & 0.41 & 0.31 & 0.53 & & 0.48 \\
\hline & $\mathrm{kW}$ & 65 & 41 & 31 & 53 & & 48 \\
\hline & WBP\% & $23 \%$ & $18 \%$ & $14 \%$ & $21 \%$ & & $19 \%$ \\
\hline \multirow{3}{*}{$\begin{array}{l}\text { Seattle Municipal } \\
\text { Tower }\end{array}$} & W/sqft & $(0.19)$ & 0.15 & 0.15 & - & & 0.03 \\
\hline & $\mathrm{kW}$ & -232 & 186 & 180 & 3 & & 34 \\
\hline & WBP\% & $-5 \%$ & $4 \%$ & $4 \%$ & $0 \%$ & & $1 \%$ \\
\hline \multirow[b]{3}{*}{ Seattle University } & W/sqft & & & & & 0.35 & 0.35 \\
\hline & $\mathrm{kW}$ & & & & & 35 & 35 \\
\hline & WBP\% & & & & & $21 \%$ & $21 \%$ \\
\hline \multirow[b]{3}{*}{ All Sites } & W/sqft & & & & & 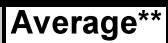 & 0.47 \\
\hline & kW & & & & & Total $^{*}$ & 338 \\
\hline & WBP\% & & & & & ${\text { Average }{ }^{\star *}}$ & $16 \%$ \\
\hline
\end{tabular}




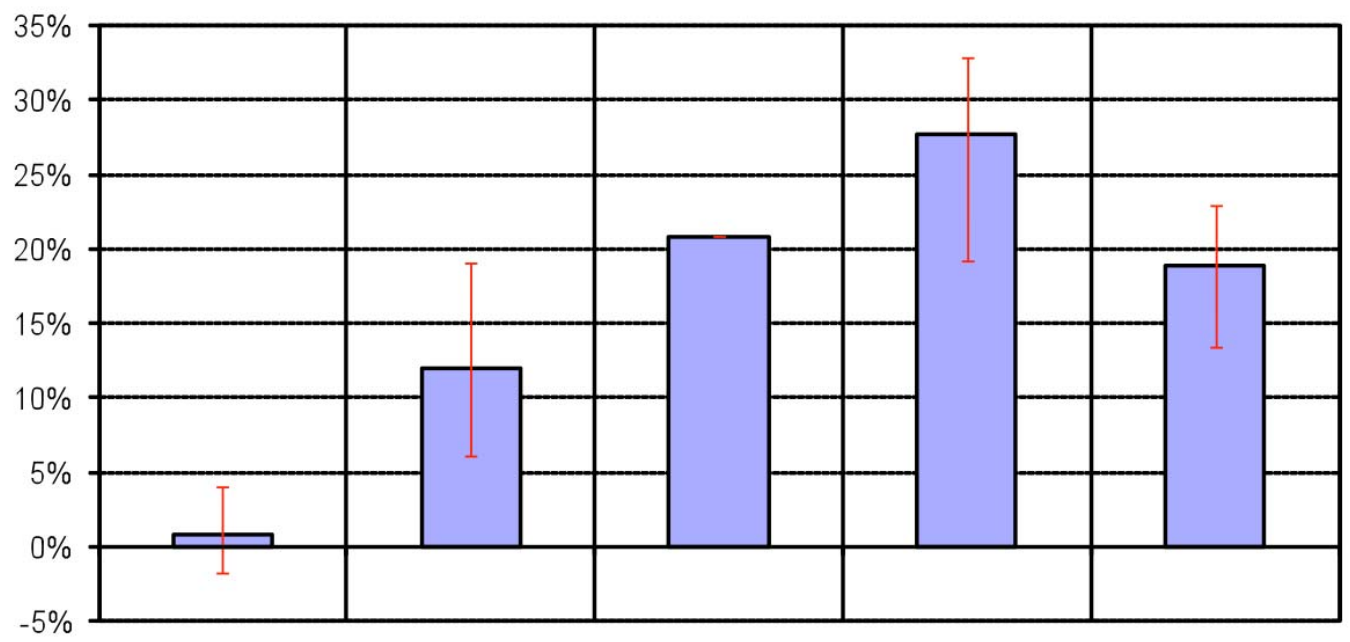

Figure 7. Average, minimum, and maximum demand reduction at each facility during summer DR events

Figure 8. Aggregate results from September 11, 2009

displays the aggregated results from the September 11, 2009 (summer) test when aggregate results yielded the best savings. For the sites in the study, the peak occurs around 3 p.m. However, the peak demand is not as pronounced as in the winter. 


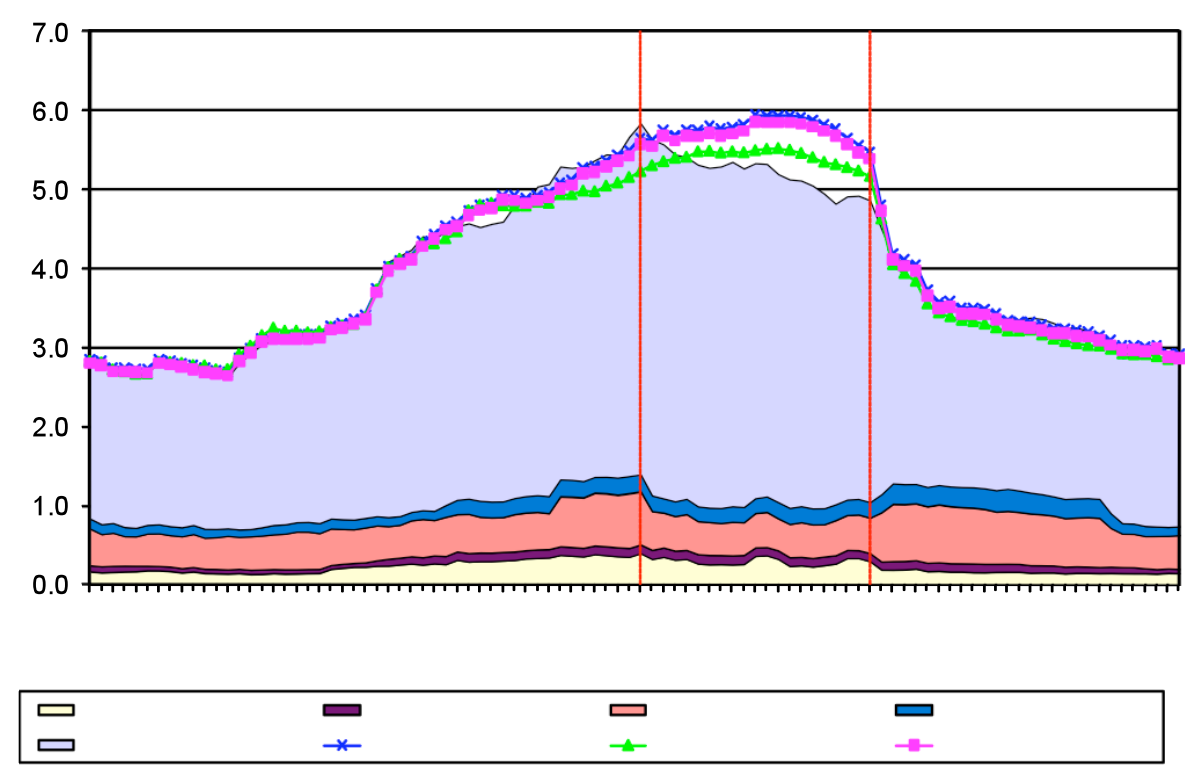

Figure 8. Aggregate results from September 11, 2009

Seattle University is excluded from the aggregate results because that site was not fully automated until September 22. McKinstry implemented pre-cooling strategies two hours before events started. It is recommended that no morning adjustments be used for sites with pre-cooling strategies. Table 9 summarizes the demand reduction for the September 11 event.

Table 9. Summary of demand reduction on September 11, 2009

\begin{tabular}{|c|c|c|c|c|c|c|c|}
\hline \multirow{2}{*}{ Baseline } & \multirow{2}{*}{ Period } & \multicolumn{2}{|c|}{ kW } & \multicolumn{2}{|c|}{ W/ft ${ }^{2}$} & \multicolumn{2}{|c|}{ WBP\% } \\
\hline & & Max & Ave & Max & Ave & Max & Ave \\
\hline \multirow{6}{*}{ OAT_MA } & $12: 00-13: 00$ & 343 & 187 & 0.21 & 0.11 & $6 \%$ & $3 \%$ \\
\hline & $13: 00-14: 00$ & 517 & 460 & 0.31 & 0.28 & $9 \%$ & $8 \%$ \\
\hline & $14: 00-15: 00$ & 731 & 621 & 0.44 & 0.37 & $12 \%$ & $11 \%$ \\
\hline & $15: 00-16: 00$ & 870 & 822 & 0.52 & 0.49 & $15 \%$ & $14 \%$ \\
\hline & $16: 00-17: 00$ & 935 & 727 & 0.56 & 0.44 & $16 \%$ & $13 \%$ \\
\hline & $12: 00-17: 00$ & 935 & 563 & 0.56 & 0.34 & $16 \%$ & $10 \%$ \\
\hline \multirow{6}{*}{$3 / 10$} & $12: 00-13: 00$ & -11 & -159 & -0.01 & -0.10 & $0 \%$ & $-3 \%$ \\
\hline & $13: 00-14: 00$ & 202 & 160 & 0.12 & 0.10 & $4 \%$ & $3 \%$ \\
\hline & $14: 00-15: 00$ & 315 & 208 & 0.19 & 0.13 & $6 \%$ & $4 \%$ \\
\hline & $15: 00-16: 00$ & 389 & 358 & 0.23 & 0.22 & $7 \%$ & $7 \%$ \\
\hline & $16: 00-17: 00$ & 485 & 361 & 0.29 & 0.22 & $9 \%$ & $7 \%$ \\
\hline & $12: 00-17: 00$ & 485 & 186 & 0.29 & 0.11 & $9 \%$ & $3 \%$ \\
\hline \multirow{6}{*}{ OATR } & $12: 00-13: 00$ & 264 & 110 & 0.16 & 0.07 & $5 \%$ & $2 \%$ \\
\hline & $13: 00-14: 00$ & 438 & 380 & 0.26 & 0.23 & $8 \%$ & $7 \%$ \\
\hline & $14: 00-15: 00$ & 645 & 537 & 0.39 & 0.32 & $11 \%$ & $9 \%$ \\
\hline & $15: 00-16: 00$ & 784 & 735 & 0.47 & 0.44 & $14 \%$ & $13 \%$ \\
\hline & $16: 00-17: 00$ & 849 & 642 & 0.51 & 0.39 & $15 \%$ & $11 \%$ \\
\hline & $12: 00-17: 00$ & 849 & 481 & 0.51 & 0.29 & $15 \%$ & $8 \%$ \\
\hline
\end{tabular}

\section{Day-Ahead versus Day-of DR Events}

The amount of time between notification and actual start of a DR event affects the type and magnitude of the response in commercial and industrial facilities. Therefore, one of the four test events each season was scheduled as a day-of event so that we could observe how a facility's response differed between day-ahead and day-of tests. Among the participants, Seattle University implemented pre-heating in the winter and pre-cooling in the summer, and McKinstry 
experimented with pre-cooling in the summer; for these sites in particular, it would be instructive to compare the day-ahead results with pre-heating/pre-cooling with day-of results without preheating/pre-cooling.

Unfortunately, neither McKinstry nor Seattle University participated in any day-of events during the summer. Seattle University did participate in three day-ahead events and one day-of event in the winter with pre-heating. Because the pre-heating period was short (only about two hours) and started at 5 a.m. (the building start-up time), it was difficult to see significant changes in the demand profile and savings from pre-heating.

\section{Performance of Each Site}

This section presents the maximum and minimum performance for each facility (Figures 9-12) and the maximum- and minimum-performing DR events (Tables 10-13). (Performance of each site for each event is presented in Appendix A). The maximum and minimum performances are selected from the calculated average percent shed for each site. Although no trend data were collected from the winter tests, the team made a concerted effort to collect trend data during the summer tests. Most EMCSs do not have enough hard drive space to collect and store more than 2-3 days' data. This limitation meant that the team had to request data soon after the events. Even with prompt data requests, some sites still had a difficult time pulling electronic files from their EMCSs.

We summarize data collected and analysis results for each site. The load shape varies from winter to summer as does the accuracy of baselines in predicting loads. In general, a baseline seems to work well when it matches demand closely during non-DR event times on the same date.

The results of the preliminary analysis were presented to the facilities on December 7, 2009. Customer responses and comments from that event are also included in our discussion below. 


\section{Seattle Municipal Tower}
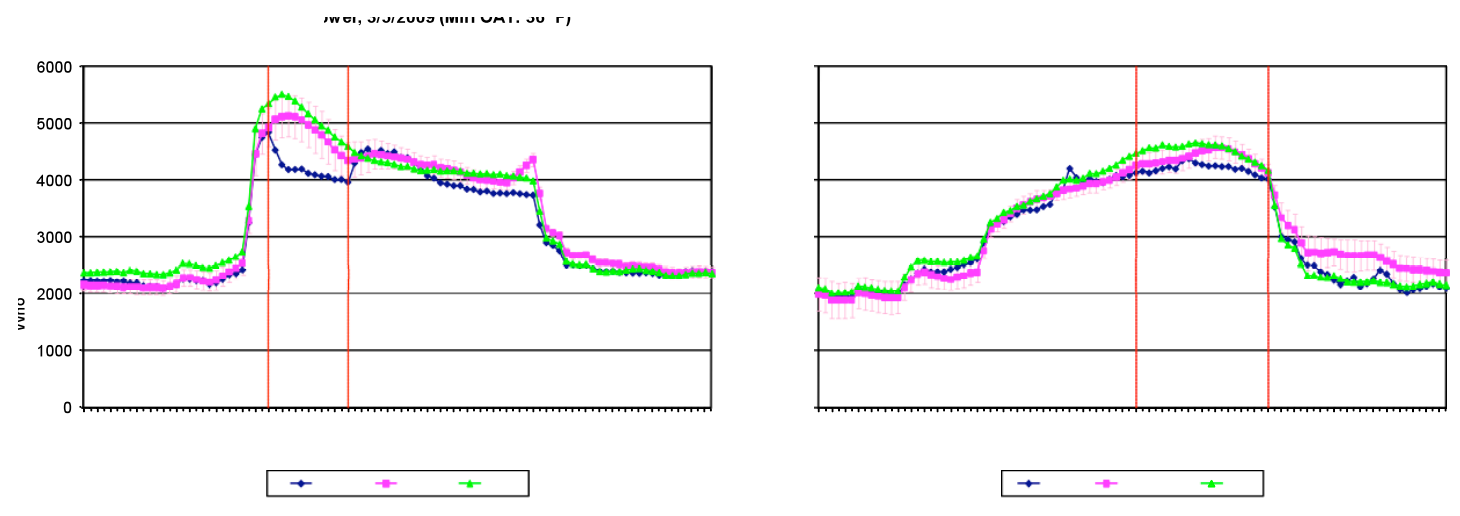

Figure 9. Maximum- and minimum-performing days for Seattle Municipal Tower in $\mathbf{2 0 0 9}$

March 5 was the maximum performance day of the winter tests for SMT. DR shed is clearly visible from the SMT load profile and is outside of the standard error of the OATR baseline. The average DR savings were $15 \%\left(0.6 \mathrm{~W} / \mathrm{ft}^{2}, 717 \mathrm{~kW}\right)$ over the three-hour DR period. March 9 was the minimum performance day, as is evident from the demand reduction levels. The DR shed is clearly visible in the graph for this event, which indicates that the automation of the event took place. However, the baseline is below the measured early morning and afternoon demand. One reason suggested by the facility for the increased morning demand was: that date was a Monday following a cold weekend, and the building had to use more heating than usual to make up for having cooled down significantly as a result of the cold weekend temperatures.

On the day of the first summer event, SMT erroneously went into pre-heating mode because a control strategy geared to the winter tests was triggered. This resulted in discomfort to occupants and early termination of the DR event. When the controls vendor investigated the problem, they reported that the day-ahead pending signal had caused the building to pre-heat as had been programmed for the winter tests. The day-ahead notification was fixed to trigger pre-cooling in the summer and pre-heating in the winter.

Maximum summer performance was observed on August 27 with a modest demand reduction of $4 \%$. The shed in the later part of the DR event is just outside of the standard error of the baseline. The shed profile is different from that of the winter tests, and the reduction seems to start at 2 p.m. instead of at noon. On September 19, the shape of the demand profile is similar to that of August 27 but above the calculated baseline.

A total of 36 control points were logged during the summer for SMT. No mapping of these control points to the actual physical space was available to the project team. Of the 36 points, 13 zones 
worked as planned. In six zones the temperature set point was adjusted automatically at noon for several minutes before it switched to normal operating temperatures after four to six minutes. The same zones were identified to have the temperature set point increased to $78^{\circ} \mathrm{F}$ at 2 p.m., continuing until 5 p.m. Eight zones registered no change in temperature set point. One zone had the temperature set point decrease to $65^{\circ} \mathrm{F}$ during the first two hours and then increase to $78^{\circ} \mathrm{F}$ at 2 p.m. Pre-cooling seemed to be working in a small number of the zones.

Commissioning was done for a representative sample of zones but not for every zone at this facility. The results suggest that comprehensive commissioning of DR strategies must be undertaken to ensure success. During the presentation of the results to the facility managers, the team was informed that the site might be included in a retrocommissioning project. We recommended that the DR strategies be included in the retrocommissioning project.

Table 10. Summary of maximum and minimum performing DR events - Seattle Municipal Tower

\begin{tabular}{|c|l|r|r|}
\hline \multicolumn{1}{|c|}{ Season } & \multicolumn{1}{c|}{ Winter } & \multicolumn{1}{c|}{ Summer } \\
\hline \hline \multirow{4}{*}{ Maximum } & Event Date & $3 / 5 / 2009$ & $8 / 27 / 2009$ \\
\cline { 2 - 4 } & $\mathrm{kW}$ & 717 & 186 \\
\cline { 2 - 4 } & $\mathrm{W} / \mathrm{ft}^{2}$ & 0.60 & 0.16 \\
\cline { 2 - 4 } & $\mathrm{WBP} \%$ & $15 \%$ & $4 \%$ \\
\hline \multirow{5}{*}{ Minimum } & Event Date & $3 / 9 / 2009$ & $8 / 19 / 2009$ \\
\cline { 2 - 5 } & $\mathrm{kW}$ & 220 & -232 \\
\cline { 2 - 4 } & $\mathrm{W} / \mathrm{ft}^{2}$ & 0.18 & -0.19 \\
\cline { 2 - 4 } & $\mathrm{WBP} \%$ & $4 \%$ & $-5 \%$ \\
\hline
\end{tabular}




\section{Seattle University}

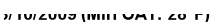

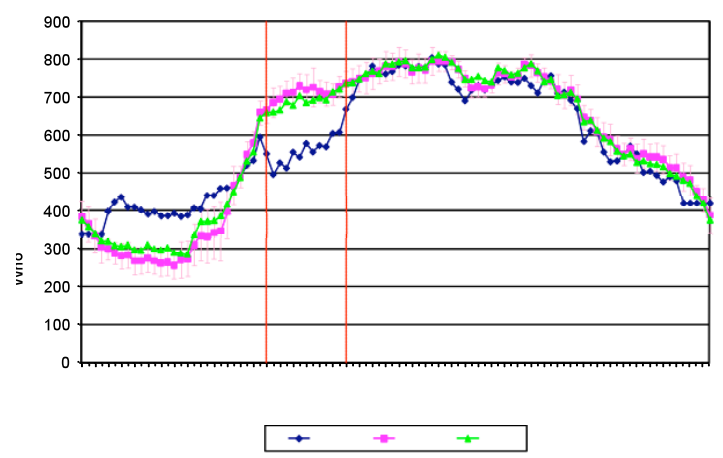

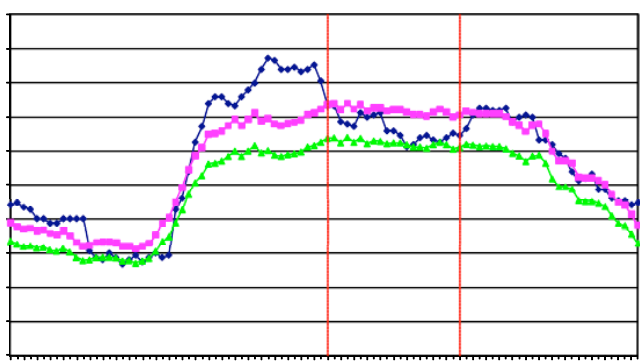

$\rightarrow \quad-\quad+$

Figure 10. Maximum- and minimum-performing days for Seattle University in 2009

Seattle University consistently participated in the winter events and delivered load sheds outside of the standard error of the baseline (see Table 11). The winter peak in is about five times higher than the summer peak. However, the summer and winter demand profiles are similar in shape. In the summer, because of a change in the building's IT system, the CLIR box was not operational until the last event. The site tried to participate manually in DR events before the automation link was established. September 15 is one of the manual events. September 22 is the only automated event. LBNL can only develop an averaging baseline for this site because of lack of historical data. The averaging baseline is adjusted using the late afternoon period because of the precooling strategy utilized at this site in the morning. No trend log data were made available from this site. 
Table 11. Summary of maximum and minimum performing DR events - Seattle University

\begin{tabular}{|c|l|r|r|}
\hline \multicolumn{1}{|c|}{ Season } & \multicolumn{1}{c|}{ Winter } & \multicolumn{1}{c|}{ Summer } \\
\hline \hline \multirow{5}{*}{ Performance } & Event Date & $3 / 10 / 2009$ & $9 / 22 / 2009$ \\
\cline { 2 - 4 } & $\mathrm{kVA}$ & 141 & 11 \\
\cline { 2 - 5 } & $\mathrm{VA} / \mathrm{ft}^{2}$ & 1.41 & $0.11 \mathrm{~W} / \mathrm{ft}^{2}$ \\
\cline { 2 - 4 } & WBP\% & $20 \%$ & $8 \%$ \\
\hline \multirow{5}{*}{ Minimum } & Event Date & $3 / 12 / 2009$ & \\
\cline { 2 - 5 } & $\mathrm{kVA}$ & 102 & \\
\cline { 2 - 5 } & $\mathrm{VA} / \mathrm{ft}^{2}$ & 1.02 & \\
\cline { 2 - 5 } & WBP\% & $15 \%$ & \\
\hline
\end{tabular}

\section{McKinstry}
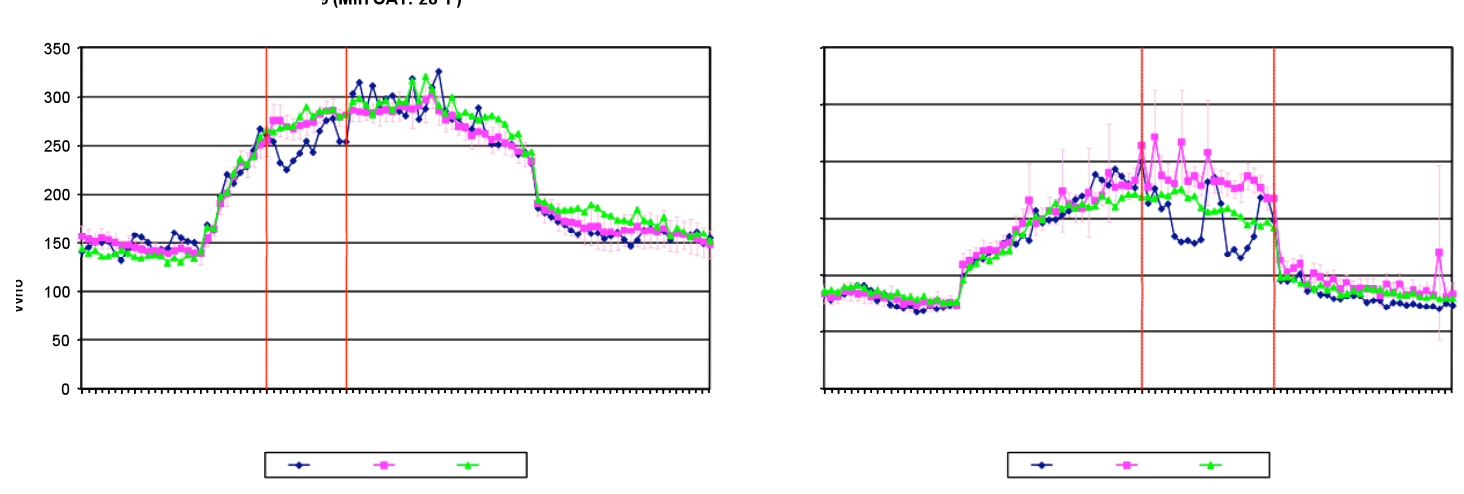

Figure 11. Minimum- and maximum-performing days for McKinstry in 2009

McKinstry was the most challenging site of the five sites. The savings from winter test were generally low because the building has gas heating, so only limited savings were possible from the fans in the small number of RTUs that were being cycled. Although small, the winter demand reduction was visible and consistently outside of the standard error of the baseline. On two of the five days of the summer tests, the building went into heating mode; when this was realized, the set points were adjusted manually. The September 11 event was one of the two events when 
heating mode was triggered; although significant savings resulted, the facilities group reported receiving many complaints from building occupants. The minimum performance day for this site was August 19 when demand savings were negligible.

Table 12. Summary of maximum and minimum performing DR events - McKinstry

\begin{tabular}{|c|l|r|r|}
\hline \multicolumn{1}{|c|}{ Season } & \multicolumn{1}{c|}{ Winter } & \multicolumn{1}{c|}{ Summer } \\
\hline \hline \multirow{3}{*}{ Merformance } & Event Date & $3 / 11 / 2009$ & $9 / 11 / 2009$ \\
\cline { 2 - 4 } & $\mathrm{kW}$ & 27 & 79 \\
\cline { 2 - 5 } & $\mathrm{W} / \mathrm{ft}^{2}$ & 0.27 & 0.79 \\
\cline { 2 - 5 } & WBP\% & $10 \%$ & $21 \%$ \\
\hline \multirow{5}{*}{ Minimum } & Event Date & $3 / 5 / 2009$ & $8 / 19 / 2009$ \\
\cline { 2 - 5 } & $\mathrm{kW}$ & 15 & 8 \\
\cline { 2 - 5 } & $\mathrm{W} / \mathrm{ft}^{2}$ & 0.15 & 0.08 \\
\cline { 2 - 5 } & $\mathrm{WBP} \%$ & $5 \%$ & $2 \%$ \\
\hline
\end{tabular}

\section{Target (T1284)}

Target store 1284 successfully participated in both the winter and summer DR events with consistent and repeated load sheds. In the first hour of the winter DR events, the store was not open. During this time, the DR savings were from HVAC set point adjustments. At 8 a.m. when the store was opened and all the lights were typically turned on, the DR savings were from turning on only half of the lights. The tests were conducted two days after the meter was installed, so there were not enough data to develop an OATR winter baseline for this site. The magnitude and the shape of the summer sheds for this site are impressive. The site consistently delivered between $19 \%$ and $40 \%$ shed over the five-hour DR period with no after-DR-event rebounds. The maximum performance was when the outside air temperature was $83^{\circ} \mathrm{F}$, and the peak load was around $700 \mathrm{~kW}$. The minimum performance occurred when the outside air temperature was 88 ${ }^{\circ} \mathrm{F}$, and the peak load was around $500 \mathrm{~kW}$. One way to explain this may be that the facility's peak load depends on internal loads, so this may not be a weather-sensitive site. Additional historical electric meter data can be used to enhance this analysis.

Target staff commented on the low light levels during the winter mornings, especially around the fitting room area. Rewiring of lights in that area excluded them from being shut off during the DR events. 


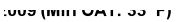

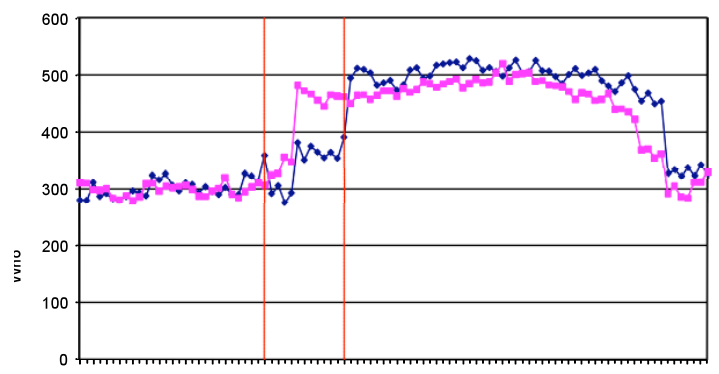

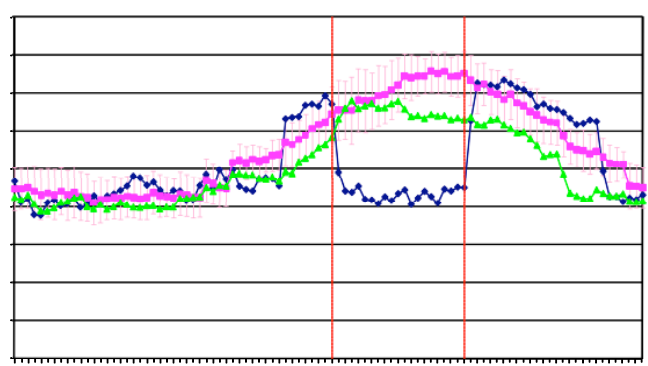

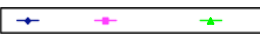

Figure 12. Maximum- and minimum-performing days for Target (T1284) in 2009

Table 13. Summary of maximum and minimum performing DR events - Target (T1284)

\begin{tabular}{|c|l|r|r|}
\hline \multicolumn{1}{|c|}{ Season } & \multicolumn{1}{c|}{ Winter } & \multicolumn{1}{c|}{ Summer } \\
\hline \hline \multirow{3}{*}{ Merformance } & Event Date & $3 / 9 / 2009$ & $9 / 11 / 2009$ \\
\cline { 2 - 5 } & $\mathrm{kW}$ & 104 & 284 \\
\cline { 2 - 5 } & $\mathrm{W} / \mathrm{ft}^{2}$ & 0.63 & 1.72 \\
\cline { 2 - 5 } & WBP\% & $19 \%$ & $40 \%$ \\
\hline \multirow{3}{*}{ Minimum } & Event Date & $3 / 3 / 2009$ & $9 / 15 / 2009$ \\
\cline { 2 - 5 } & $\mathrm{kW}$ & 102 & 94 \\
\cline { 2 - 5 } & W/ft & 0.62 & 0.57 \\
\cline { 2 - 5 } & WBP\% & $19 \%$ & $19 \%$ \\
\hline
\end{tabular}

Trend logs were collected, including zone temperatures serviced by the 12 RTUs that were controlled during the DR events. Figure 13 displays the zone temperatures on August 19. Although it takes four to five hours for a few of the zone temperatures to increase by $4^{\circ} \mathrm{F}$, temperatures in a majority of the zones increased by $4^{\circ} \mathrm{F}$ within the first two to three hours and oscillated around the set point. The observed temperature increase was most rapid in the office and guest services areas and slowest in the pharmacy and conference room areas. 


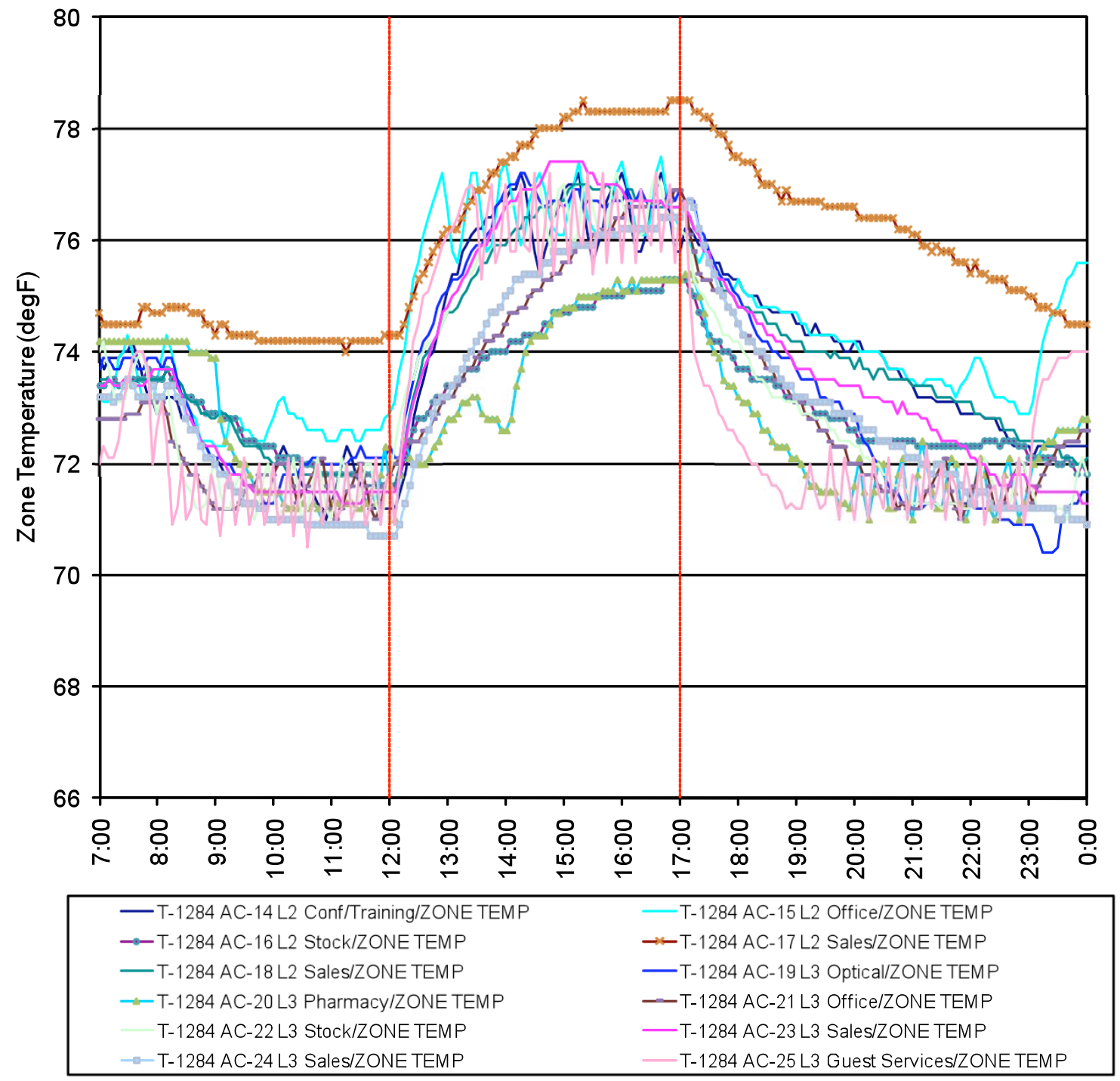

Figure 13. Zone temperatures from August 19, 2009 DR event in Target (T1284)

\section{Target (T0637)}

Although Target store 0637 participated in both winter and summer DR events, the winter meter data were corrupted, so we had to exclude them from the winter results (Kiliccote et al. 2009). However, this site continued to participate in DR events during the summer, and the meter data were captured for a few days before the events. Therefore, the averaging baseline was used to calculate the load sheds. This store is smaller than the other Target store in the study, and its load shape is also different. After the shed period, the measured demand was higher than the baseline, indicating a rebound in the first hour and higher demand in the following hours.

No trend logs were available from this site. 

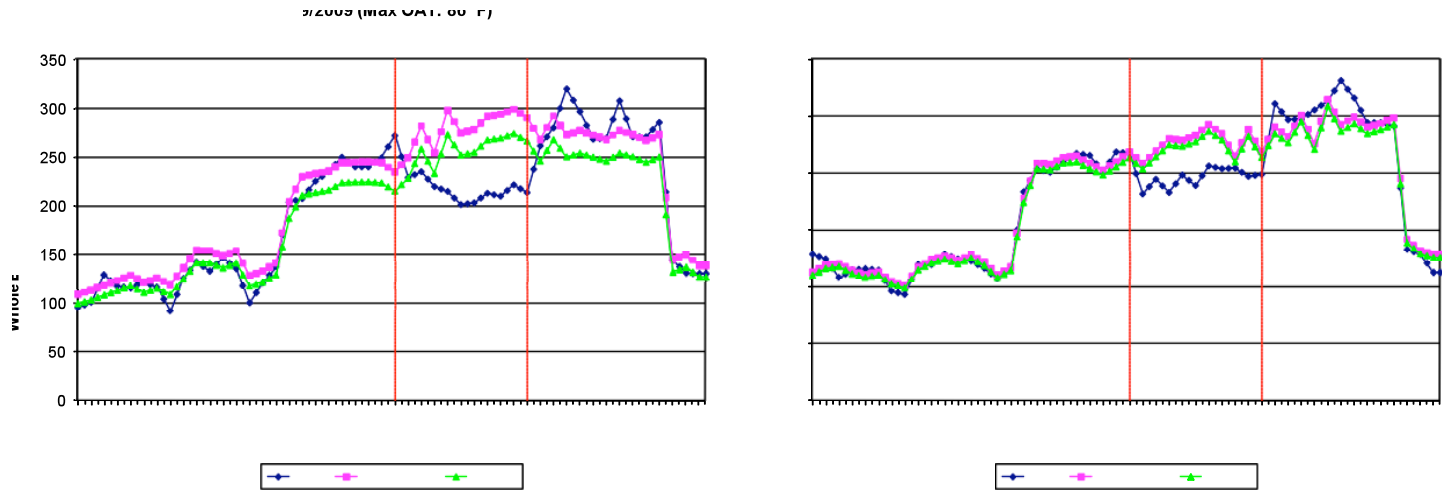

Figure 14. Maximum- and minimum-performing days for Target (T0637) in 2009

Table 14. Summary of maximum and minimum performing DR events - Target (T0637)

\begin{tabular}{|c|l|r|}
\hline \multicolumn{1}{|c|}{ Performance } & \multicolumn{1}{c|}{ Season } & \multicolumn{1}{c|}{ Summer } \\
\hline \hline \multirow{4}{*}{ Maximum } & Event Date & $8 / 19 / 2009$ \\
\cline { 2 - 3 } & $\mathrm{kW}$ & 65 \\
\cline { 2 - 3 } & $\mathrm{W} / \mathrm{ft}^{2}$ & 0.65 \\
\cline { 2 - 3 } & WBP\% & $23 \%$ \\
\hline \multirow{5}{*}{ Minimum } & Event Date & $9 / 11 / 2009$ \\
\cline { 2 - 3 } & $\mathrm{kW}$ & 31 \\
\cline { 2 - 3 } & $\mathrm{W} / \mathrm{ft}^{2}$ & 0.31 \\
\cline { 2 - 3 } & WBP\% & $14 \%$ \\
\hline
\end{tabular}




\section{Observations and Recommendations}

This section summarizes the lessons learned and recommendations from this OpenADR demonstration project. The main recommendations are to encourage SCL to expand the DR project in downtown Seattle area and to encourage BPA to facilitate the expansion of OpenADR within their control area. As a next step toward that long-term goal, LBNL recommends that SCL and BPA consider developing case studies that summarize the lessons learned by the facilities that participated in this project. In addition, whole-building energy simulation tools that are developed for estimating DR capabilities for buildings in hot summer climates can be enhanced to support estimating cold-winter-morning DR capabilities in commercial buildings. Other recommendations outline future research for developing this project into a DR program. More analysis is needed to establish the value of DR at both the wholesale and retail levels and to identify the appropriate designs that will elicit maximum value from programs.

\section{Program Design}

- OpenADR is a technology platform that enables the automation of DR in an open and interoperable manner. OpenADR implementation is expected to become less expensive over time as it develops through the National Institute of Standards and Technology process, more utilities adopt it, and more building controls companies develop products for it.

- Incentives for participating in this project included free pre-programming and commissioning of the DR strategies as well as direct payments to the customers. Maximum direct winter and summer incentives were $\$ 7,000$ and $\$ 4,000$, respectively. Although summer incentives were lower, the sites that participated in the winter tests continued to participate in the summer tests.

\section{Recommendation:}

1. The local and regional value and the purpose of DR should be determined before DR programs are designed and automated to determine equitable incentives.

\section{Recruitment}

- Recruitment is a lengthy and ongoing effort. The team's experience in the northwest was similar to experiences with early field test recruitment in California. Recruitment is part education and part relationship building. DR participants must be comfortable that:

- the service levels in their facilities will be modified for periods of time;

- ongoing assistance and monitoring will help them select detectable but acceptable DR strategies; and

- strategies can be modified following DR events, and participants can choose not to participate in an individual event by opting out through the DRAS internet portal.

- A large potential pool of customers enabled us to enroll the targeted number of participants. Of the 11 facilities initially surveyed, eight sites indicated interest in participating in the study. Of these eight, three could not participate in the test events because of one or more of the following:

- Limitations within control systems and the increased cost of overcoming these limitations, 
- Communication problems within the control systems that prevented the research team from monitoring and collecting data from each test DR event,

- Concerns from tenants.

\section{Recommendations:}

1. Many large buildings in the downtown Seattle area participate in SCL's MeterWatch service, which provides customers with interval meters and makes their data available to them through the internet. Interval meters, which record customers' data in 15-minute intervals, are required for measurement and verification of DR participation. The downtown sites participating in the MeterWatch service are excellent candidates to start expanding the DR project.

2. Extensive customer education and outreach are required for a DR program. Education should address why DR is necessary, what customers can do, and how they will be compensated. SCL would like to use OpenADR for reliability purposes, so the value stream both to the utility and to the customer should be considered.

\section{Technology Deployment}

- Lighting provides year-round DR. Lighting load-sheds have fast ramp times and thus can provide excellent year-round DR although the change in lighting level is detectable by building occupants. However, centralized controls are necessary for DR with lighting systems, and most lighting control systems are not centralized. Most new lighting control systems that integrate with daylighting in commercial buildings have local closed-loop controls.

- HVAC systems with natural gas heating have limited savings opportunities for winter DR. Two buildings with gas-powered rooftop units selected duty cycling as a DR strategy. The DR opportunities in these types of systems come from fan power savings. (Electric heating systems, in contrast, offer significant savings from fan power reductions, see below).

- All-electric heating systems offer good opportunities for winter DR. A global zonetemperature adjustment strategy, which is often used in California to reduce peak demand during summer afternoons, performed well in the electrically heated building in this study. Zone temperatures were temporarily reduced to minimize electric loads.

- OpenADR systems can be used for both winter and summer DR in commercial buildings. On average, using the outside air temperature regression baseline, the buildings that participated in the winter DR events delivered $14 \%$ demand reduction per site or 0.57 $\mathrm{W} / \mathrm{ft}^{2}$ over three hours. The summer DR events delivered $16 \%$ demand reduction per site or $0.43 \mathrm{~W} / \mathrm{ft}^{2}$ over five hours. HVAC and lighting systems appear to present major opportunities for automated DR in commercial buildings for both winter and summer loads. In this study, both HVAC systems with electric heating and gas heating provided DR opportunities because there are significant savings from fan power.. Average demand reductions for winter and summer events were $730 \mathrm{~kW}$ and $481 \mathrm{~kW}$, or $12 \%$ and $8 \%$ of aggregate peak load, respectively. Error! Reference source not found. presents a summary of results from winter and summer DR events (using the OATR baseline)

Table 15. Summary of winter and summer DR event results (using OATR baseline)

\begin{tabular}{|l|r|r|}
\hline & \multicolumn{1}{|c|}{ Winter } & \multicolumn{1}{c|}{ Summer } \\
\hline \hline Average demand reduction (kW) for each DR event & $767 \mathrm{~kW}$ & $338 \mathrm{~kW}$ \\
\hline Total energy savings from four DR events (kWh) & $8,589 \mathrm{kWh}$ & $6,455 \mathrm{kWh}$ \\
\hline Average per customer cost for control and commissioning & $\$ 4,057$ & $\$ 4,962$ \\
\hline Average control and commisionning cost per kW (one time) & $\$ 76 / \mathrm{kW}$ & $\$ 108 / \mathrm{kW}$ \\
\hline
\end{tabular}


- Commissioning of DR strategies plays an important role in the success of DR in dualpeaking regions. During the DR tests, the sites did not have a way to trigger the eventpending signal through their interface ("mysite" webpage). The experience from the summer DR tests shows that customers need to be able to replicate all DR operating modes (DR event pending, DR strategy active, and DR strategy idle) to properly commission and test the DR control strategies. A significant finding is the importance of having the ability to trigger the pending signal manually, which was not possible in this test and caused problems for several sites. Commissioning of all of the signals improves the reliability of DR strategies.

- DR works best in well-tuned buildings. For one building where the DR performed well in the winter, the summer DR strategies did not perform well because the sequence of operations did not maintain zone temperatures.

\section{Recommendations:}

1. Successful technology deployment requires a workforce that understands the technology and the new ways of using it. Education of controls vendors is recommended, on DR, the OpenADR communication platform, and DR strategies.

2. Commissioning building systems and DR strategies are important to the success of DR implementation. DR programs can be incorporated in retrocommissioning programs. The retrocommissioning team can work with the customer to develop, implement, and commission DR strategies. The added cost of this to a retrocommissioning project is expected to be lower than for stand-alone individual DR projects. 


\section{References}

Coughlin, K., M.A. Piette, C. Goldman and S. Kiliccote. 2008. Estimating Demand Response Load Impacts: Evaluation of Baseline Load Models for Non-Residential Building in California. Lawrence Berkeley National Laboratory report LBNL-63728. January.

Goldberg, M.L., G. Kennedy Agnew. 2003. Protocol Development for Demand-Response Calculations: Findings and Recommendations. KEMA-Xenergy, California Energy Commission Report CEC 400-02-017F.

Kiliccote, S., M.A. Piette, G. Wikler, J. Prijyanonda, and A. Chiu. 2008. "Installation and Commissioning Automated Demand Response Systems." Proceedings, $16^{\text {th }}$ National Conference on Building Commissioning, Newport Beach, CA, April 22-24, 2008. Lawrence Berkeley National Laboratory report LBNL-187E. April.

Motegi, N., M.A. Piette, D.S. Watson, S. Kiliccote, P. Xu. 2007. Introduction to Commercial Building Control Strategies and Techniques for Demand Response. California Energy Commission Lawrence Berkeley National Laboratory report LBNL-59975. May.

Piette, M.A., D.S. Watson, N. Motegi, and N. Bourassa. 2005. Findings from the 2004 Fully Automated Demand Response Tests in Large Facilities. Lawrence Berkeley National Laboratory LBNL-58178. September.

Piette, Mary Ann, Girish Ghatikar, Sila Kiliccote, Ed Koch, Dan Hennage, Peter Palensky, and Charles McParland. 2009. CEC OpenADR-Version 1.0 Report 2009. Open Automated Demand Response Communications Specification (Version 1.0). California Energy Commission report CEC-500-2009-063 and Lawrence Berkeley National Laboratory report LBNL-1779E.

Quantum Consulting and Summit Blue Consulting. 2004. Working Group 2 Demand Response. Program Evaluation. Program Year 2004. Final Report. December.

Wikler, Greg, I. Bran, J. Prijyandonda, S. Yoshida, K. Smith (Global Energy Partners, LLC), M.A. Piette, S. Kiliccote, G. Ghatikar (Lawrence Berkeley National Laboratory), D. Hennage (Akuacom, Inc.), and C. Thomas (Electric Power Research Institute). 2008. Pacific Gas \& Electric Company 2007 Auto-DR Program: Task 13 Deliverable: Auto-DR Assessment Study. Report to PG\&E. February 11. 


\section{Glossary}

BPA

CLIR Box

DR

DRAS

DRRC

EIS

EMCS

$\mathrm{ft}^{2}$

GTA

HTTPS

HVAC

IT

kW

LBNL

MOA

OATR

OpenADR

RTU

SCL

SMT

VAV

W

XML
Bonneville Power Administration

Client Logic Internet Rely

An internet gateway device designed, built, and provided to PG\&E clients (where needed) to accept DR event signals and transmit them to the customer's EMCS for this project

demand response

strategies and programs to facilitate load shedding during peak power demand periods.

demand response automation server

An internet-based communications server and database system that produces a computer-readable, electricity price signal on a Web services server, using the meta-language XML.

Demand Response Research Center

A program at $L B N L$ funded primarily by the California Energy Commission's Public Interest Energy Research Program

energy information system

energy management and control system

square foot

global temperature adjustment

secure hyper transfer text protocol

heating, ventilation, and air conditioning

information technology

kilowatt

Lawrence Berkeley National Laboratory

memorandum of agreement

outside air temperature regression

open automated demand response

An information exchange model to communicate price and reliability signals for demand response

rooftop unit

Seattle City Light

Seattle Municipal Tower

variable air volume

watt

extensible markup language 